Editorial

\title{
Sino-Austrian High-Tech Acupuncture Network-Annual Report 2016
}

\section{Gerhard Litscher}

Research Unit for Complementary and Integrative Laser Medicine, Research Unit of Biomedical Engineering in Anesthesia and Intensive Care Medicine, and TCM Research Center Graz, Medical University of Graz, Auenbruggerplatz 29, 8036 Graz, Austria; gerhard.litscher@medunigraz.at; Tel.: +43-316-385-13907; Fax: +43-316-385-13908

Received: 15 February 2017; Accepted: 15 February 2017; Published: 22 February 2017

Abstract: The Sino-Austrian High-Tech Acupuncture Research Network was founded in 2005 and has been growing ever since. The network comprises many partners from China and is highly involved in research and education activities. This report introduces the network's activities in the year 2016.

Keywords: high-tech acupuncture; network; annual report; China; Austria

The network was founded in 2005 by Prof. DDr. Gerhard Litscher from Medical University of Graz and comprises many partners from China (see Figure 1).

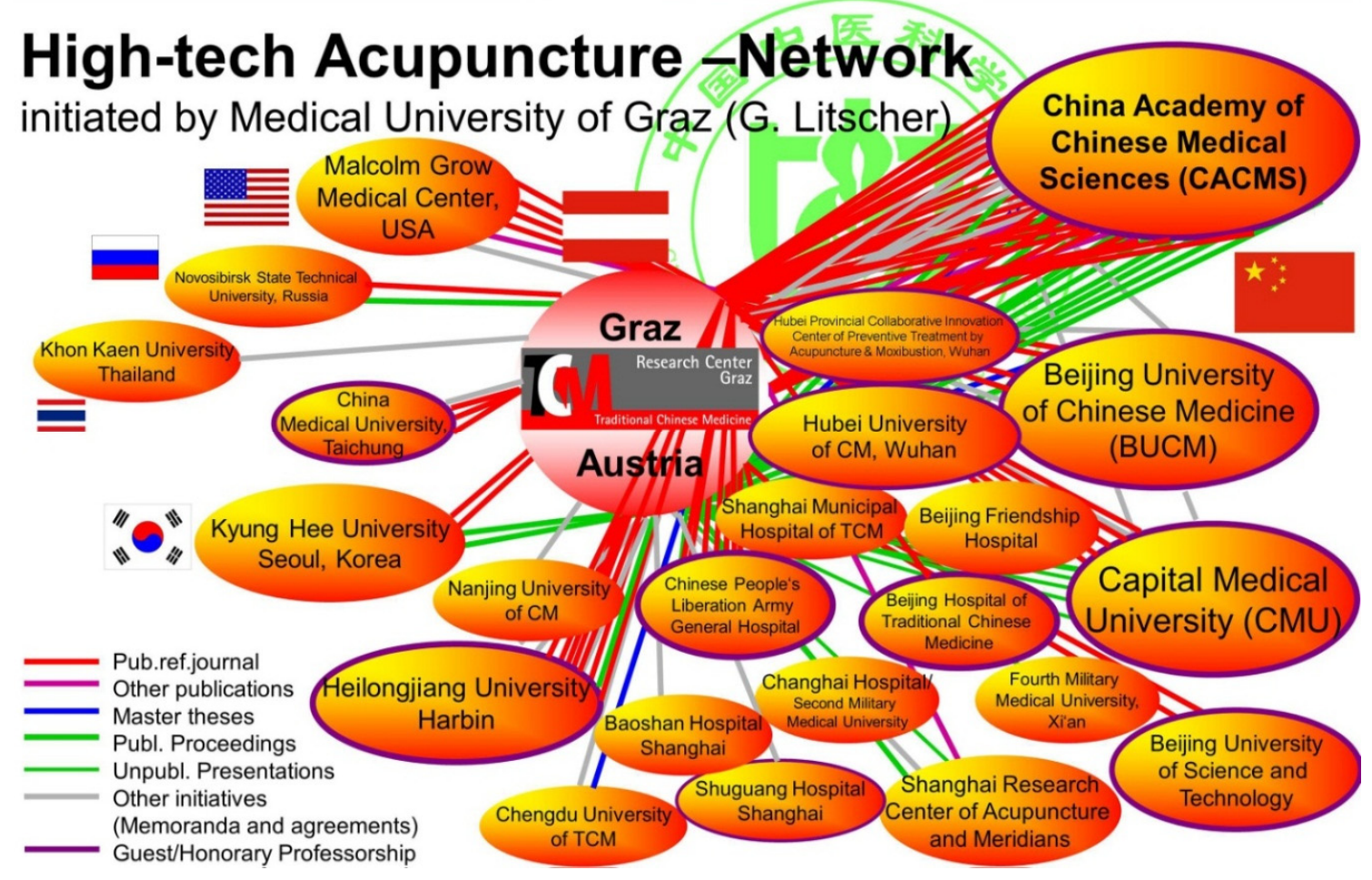

Figure 1. High-tech acupuncture network partners and scientific information.

Within 2016, the Sino-Austrian High-Tech Acupuncture Network has grown very fast. Milestones and publications [1-12] from the year 2016 are listed chronologically below:

12-19 March 2016: Spring Seminar-Arlberg, Lech-Arlberg, Austria. Function Therapies. Society for Integrative Dental Medicine, CAM in Dentistry (Figure 2). 


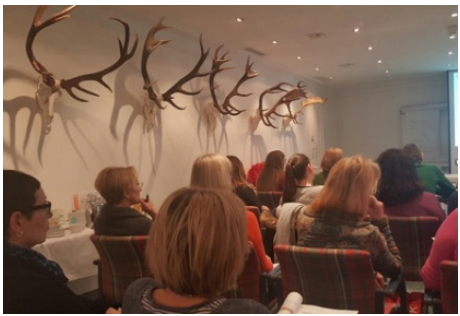

(a)

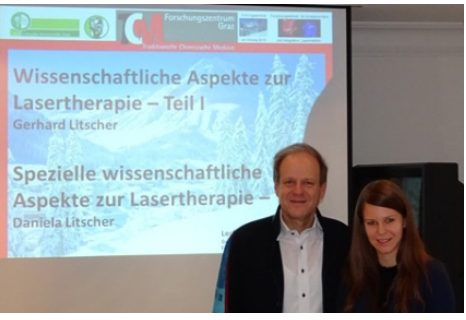

(b)

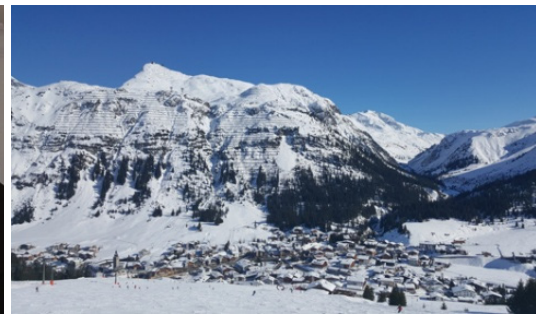

(c)

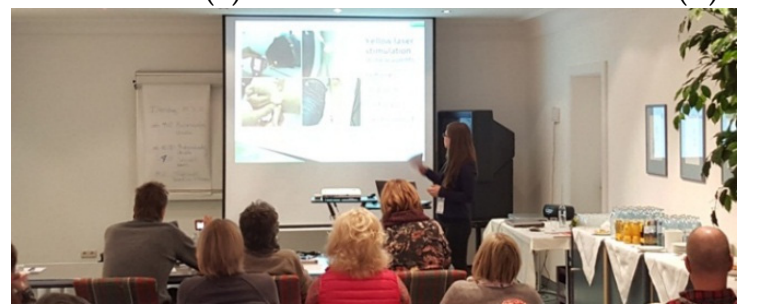

(d)

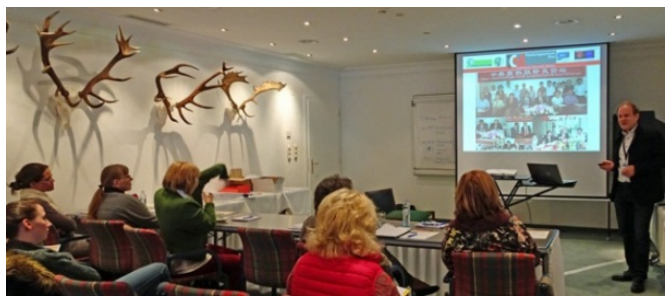

(e)

Figure 2. Three-hour seminar (a-e) from Prof. Gerhard Litscher (b left, e) and Dr. Daniela Litscher (b right, d) in Lech (c), Austria.

1 April 2016: Ohshiro Laser Therapy Best Paper Award, Tokyo, Japan, April, 2016 (Figure 3).

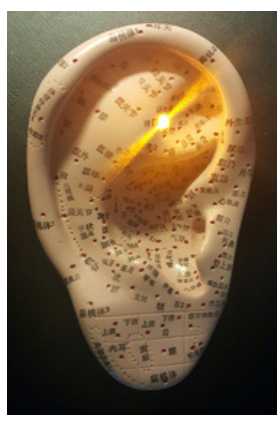

(a)

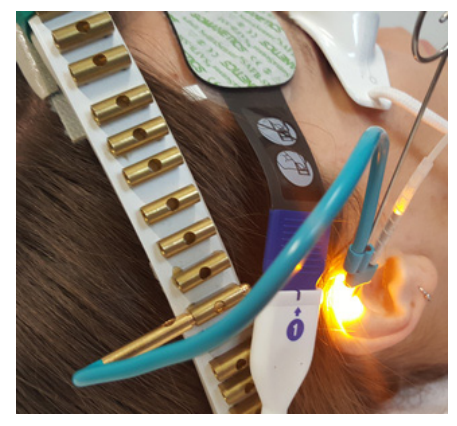

(b)

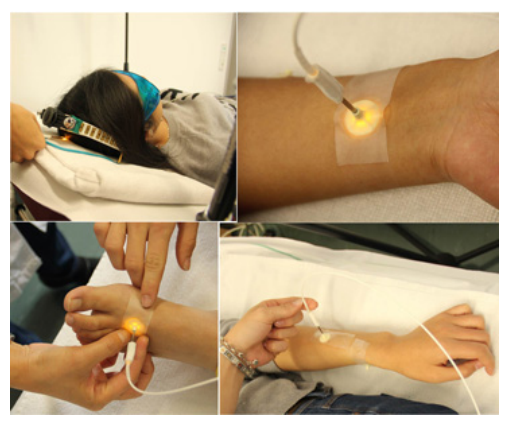

(c)

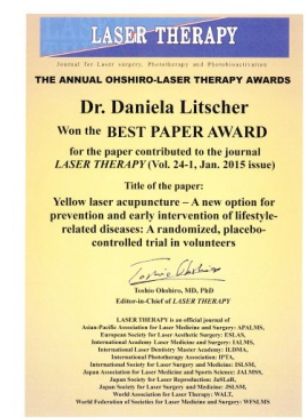

(d)

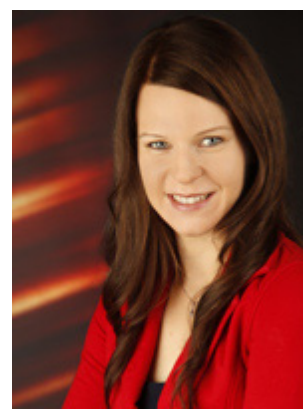

(e)

Figure 3. Dr. Daniela Litscher (e) receives Ohshiro Laser Therapy Best Paper Award (d) for 'Yellow Laser Acupuncture' (a-c).

14 May 2016: WFAS-Education Working Committee Wuhan, China, 13 May 2016. (Figure 4) [6,8]. 


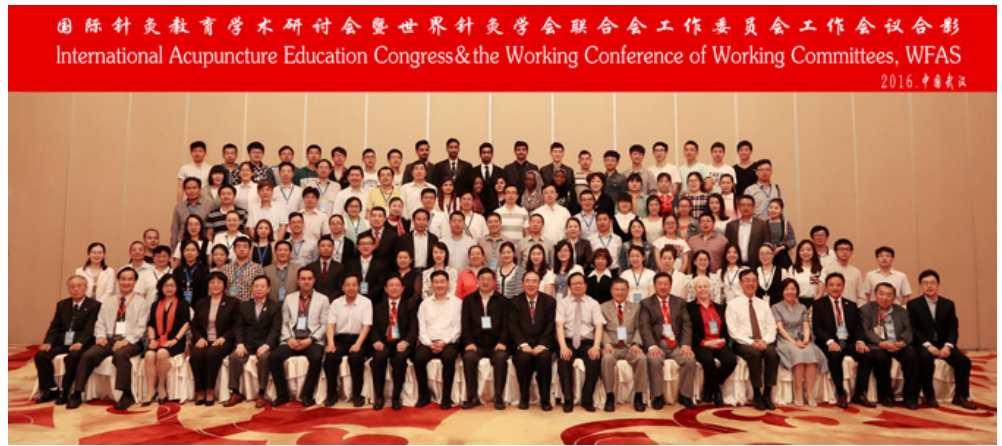

(a)

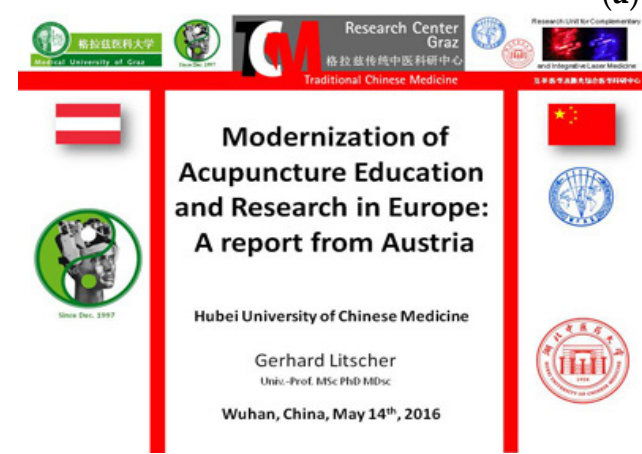

(b)

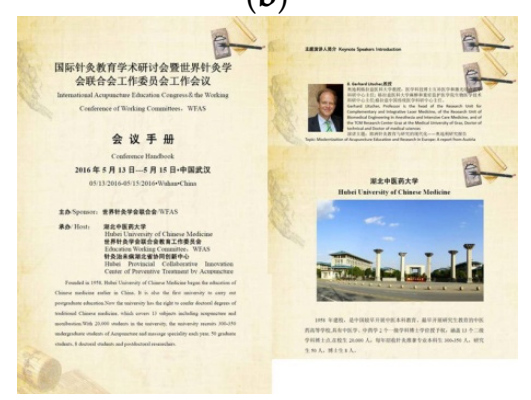

(d)

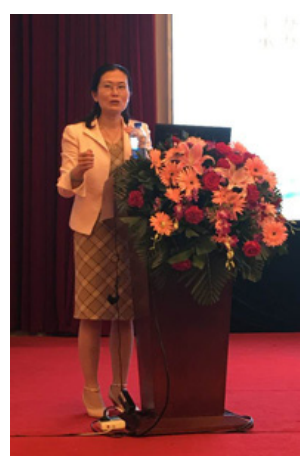

(c)

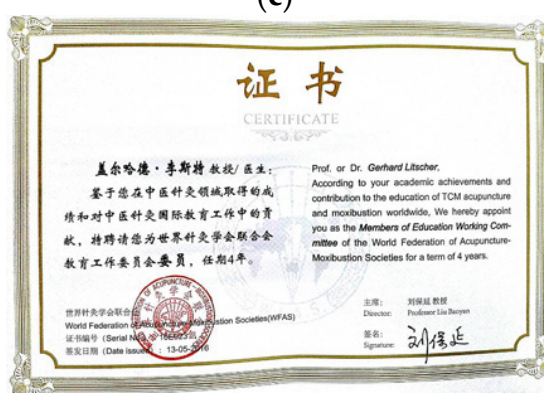

(e)

Figure 4. International Acupuncture Education Congress, Wuhan, China (a); the lecture from Prof. G. Litscher (b) was presented by Prof. Fengxia Liang (c). Prof. Gerhard Litscher was appointed as a Member of the Education Working Committee of the World Federation of Acupuncture-Moxibustion Societies for a term of 4 years $(\mathbf{d}, \mathbf{e})$.

20 May 2016: 2016 IEEE Information Technology Networking. Electronic and Automation Control Conference (Figure 5).

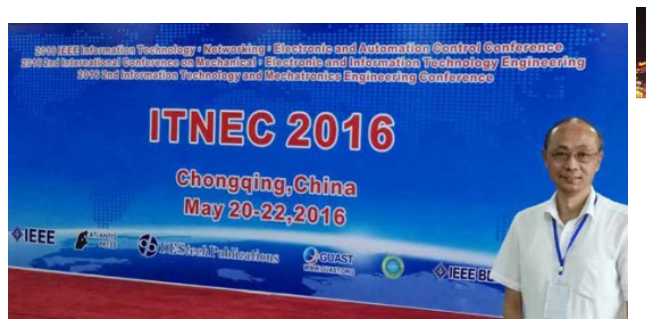

(a)

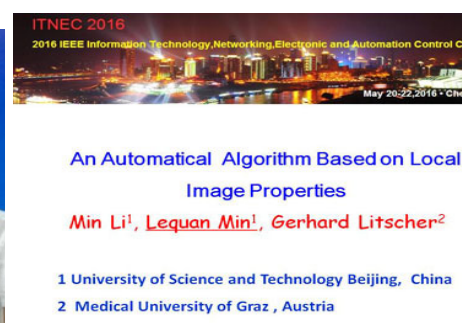

(b)

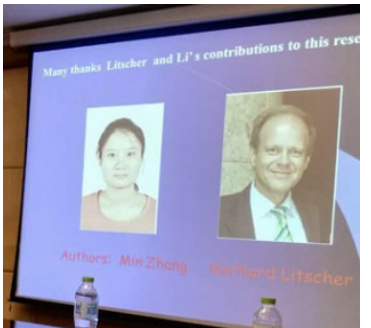

(c)

Figure 5. ITNEC 2016, Chongqing, China (a-c); the lecture (b,c) was presented by Prof. Min Lequan (a). 
10-11 June 2016: 11th International ISLA Congress for Medical Laser Applications, Beverungen, Germany (Figure 6).

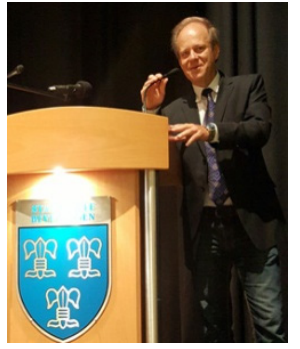

(a)

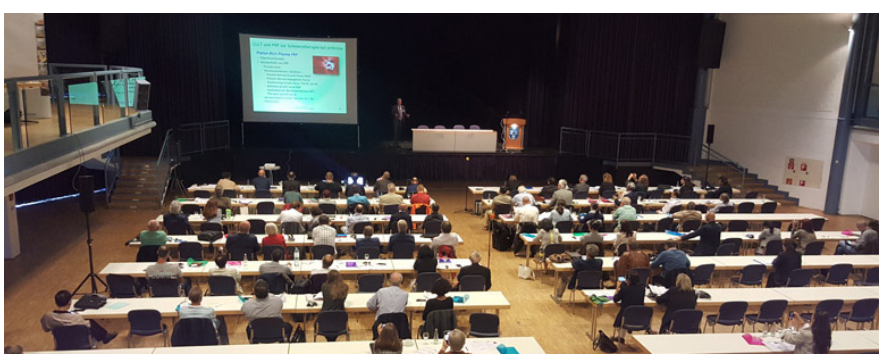

(b)

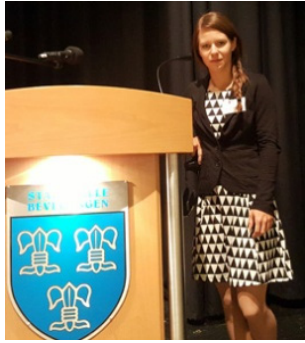

(c)

Figure 6. Opening Lecture given by Prof. Gerhard Litscher, President of ISLA $(\mathbf{a}, \mathbf{b})$. Main lecture about Nobel Prize Winner Tu Youyou given by Dr. Daniela Litscher (c).

5 July 2016: Joint research project with CACMS - China Academy of Chinese Medical Sciences (Figure 7).

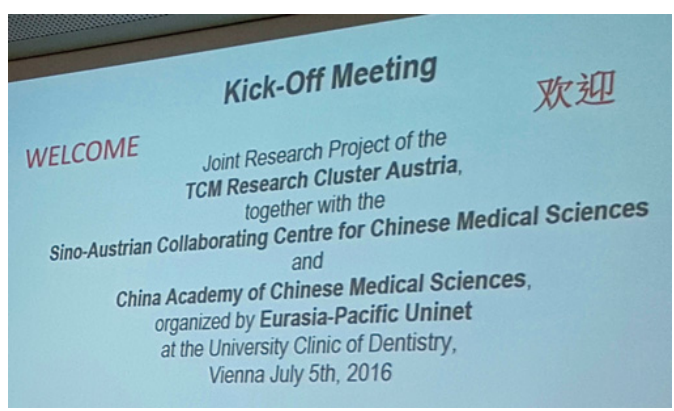

(a)

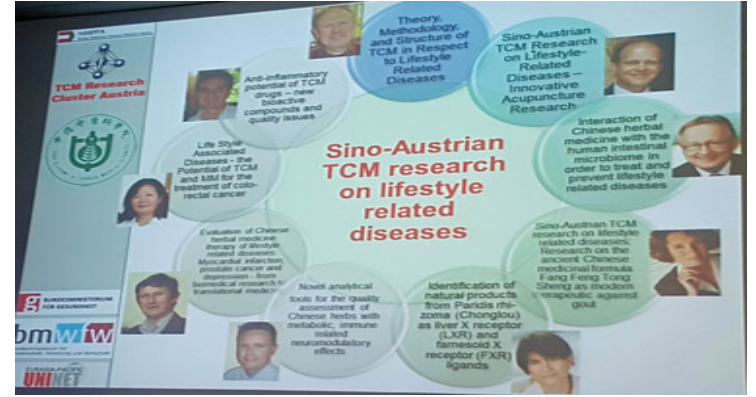

(b)

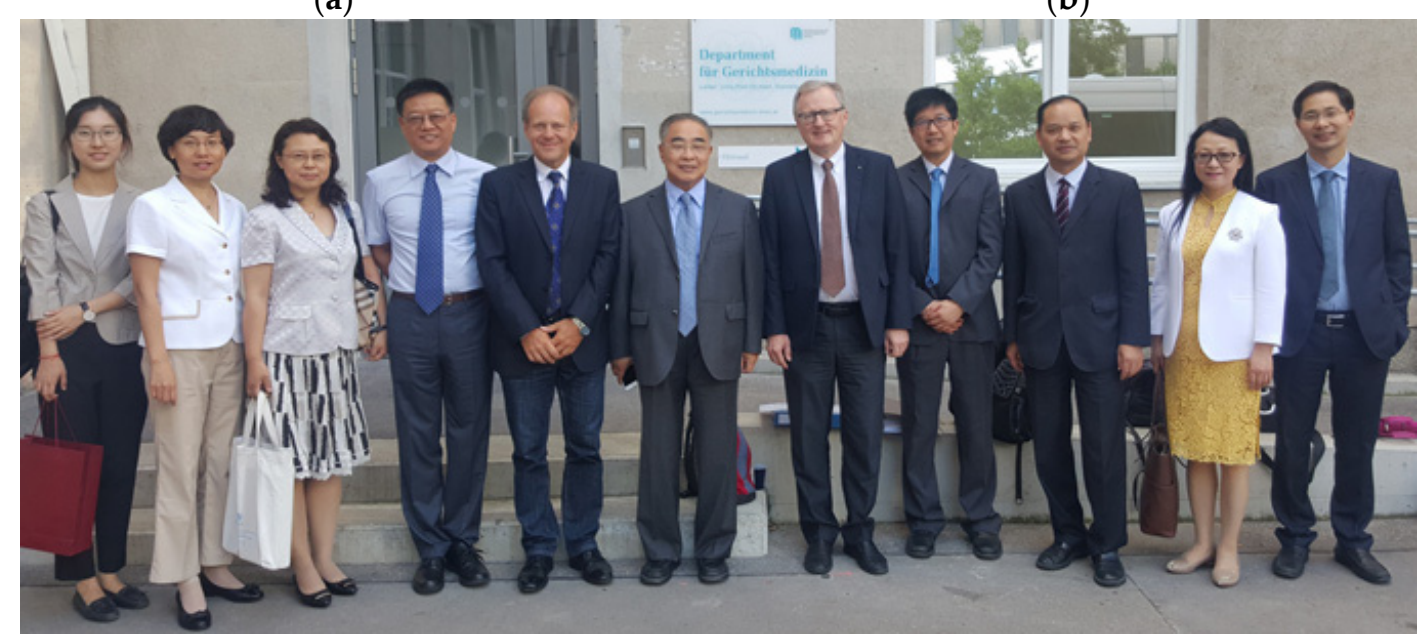

(c)

Figure 7. Kick-off Meeting of the joint project (3rd phase) (a-c). Professor Zhang Boli (c middle) with Prof. Gerhard Litscher (c middle left), Prof. Rudolf Bauer (c middle left) and the Chinese delegation in Vienna, Austria.

6 July 2016: China Academy of Chinese Medical Sciences in Graz, Austria (Figure 8) [7]. 


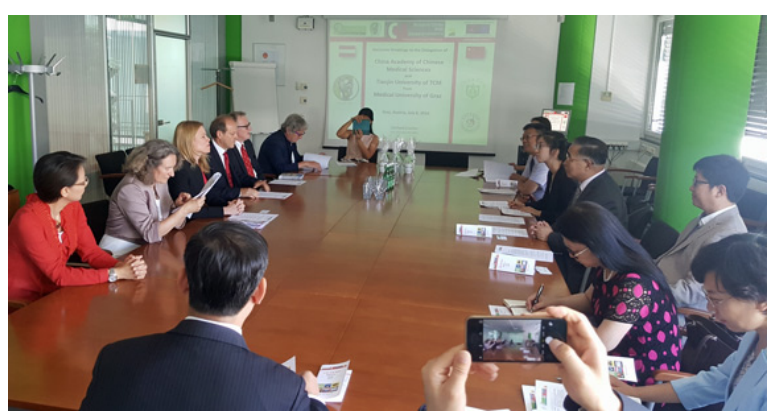

(a)

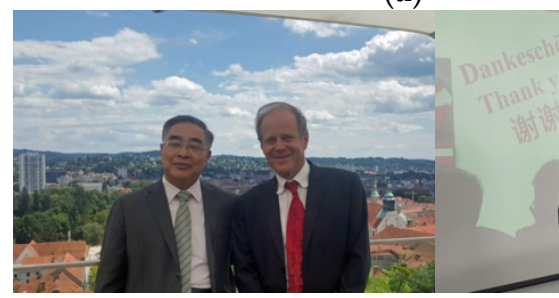

(c)

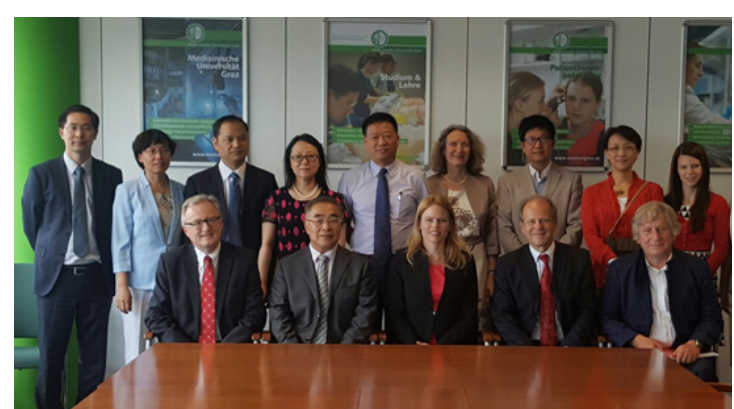

(b)

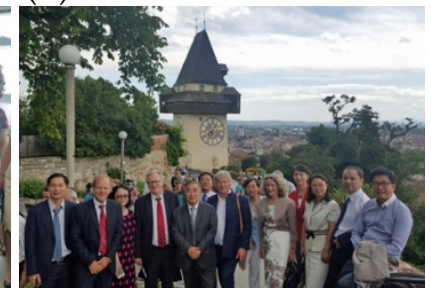

(f)

Figure 8. Meeting at Medical University of Graz (a-f). Prof. Zhang Boli, President of China Academy of Chinese Medical Sciences and Tianjin University of Traditional Chinese Medicine, and Academician of China Engineering Academy (c), Prof. Yu Xiaochun, Executive Deputy Director of Institute of Acupuncture and Moxibustion (d), Prof. Chen Shilin, Director of Institute of Chinese Materia Medica (e), with Prof. Gerhard Litscher (c left) and Dr. Daniela Litscher (e right).

Established in 1955, China Academy of Chinese Medical Sciences (hereafter abbreviated as CACMS) is China's largest comprehensive research institute combining scientific research, medical treatment and teaching that is directly under the State Administration of TCM (traditional Chinese medicine). It boasts various disciplines, advanced equipment and great research strength and has under it 17 research institutes, six medical institutions, one graduate school, two branch schools, two pharmaceutical companies and publishing houses of ancient books on Chinese medical science. Besides, it is a founder of 13 kinds of academic journals on Chinese medical science.

What is especially worth mentioning is the achievement in artemisinin research, which provided a powerful weapon for humans against malaria and saved hundreds of thousands of lives, making tremendous contributions for human health, and thus CACMS were awarded by Lasker Medical Research Award and in 2015 the Nobel Prize in Medicine (Prof. Tu Youyou).

Acupuncture is one of the key disciplines of research of this renowned institution. Medical University of Graz (Prof. Gerhard Litscher) has a close cooperation with China Academy of Chinese Medical Sciences (with Prof. Yu Xiaochun) for more than 10 years, and also some activities with Tianjin University of Traditional Chinese Medicine on the topic of high-tech acupuncture research. Within the last years, more than 60 joint SCI/PubMed-listed publications have been published with CACMS alone. Prof. Litscher from Medical University of Graz is Visiting Professor at the Institute of Acupuncture and Moxibustion at CACMS.

25 July 2016: New Book-Heart Rate Variability and Acupuncture, Graz, Austria. Contact and order: gerhard.litscher@medunigraz.at (Figure 9). 


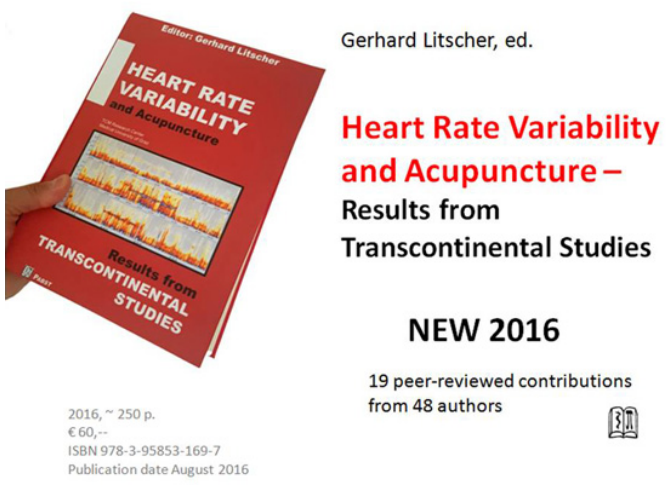

(a)

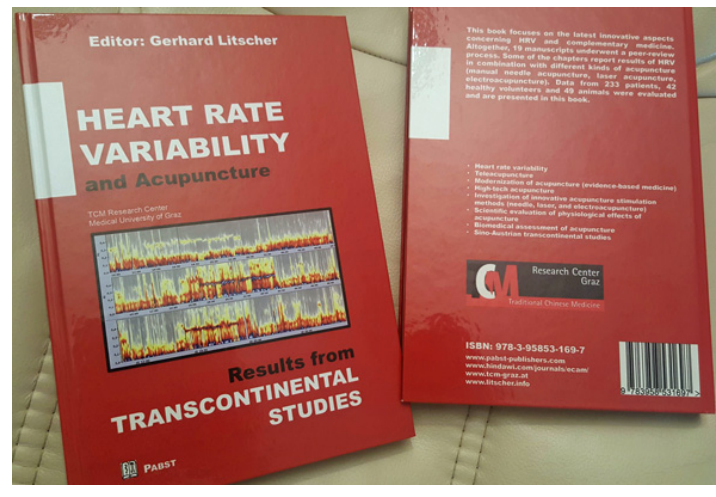

(b)

Figure 9. Heart rate variability and acupuncture-results from transcontinental studies $(\mathbf{a}, \mathbf{b})$.

25 July 2016: New Study—Laser Watch, Graz, Austria (Figure 10) [10].

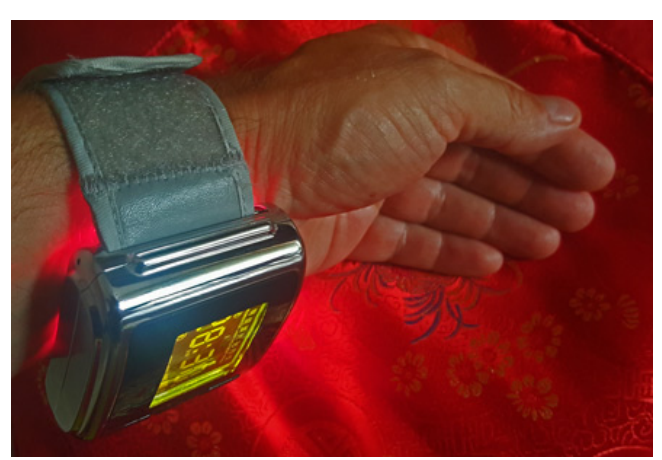

(a)

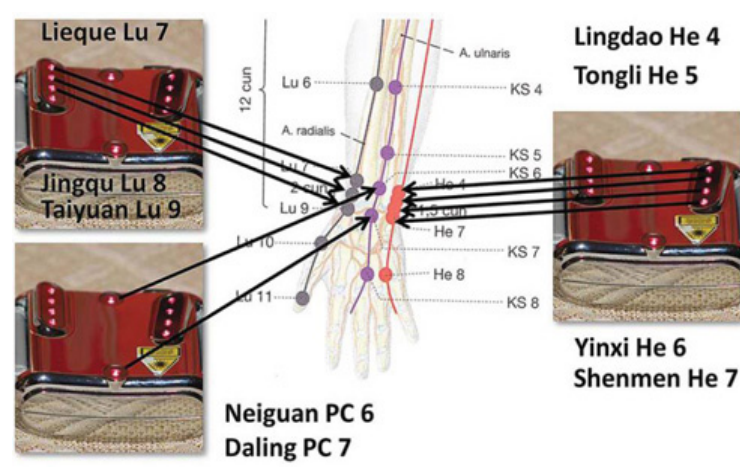

(b)

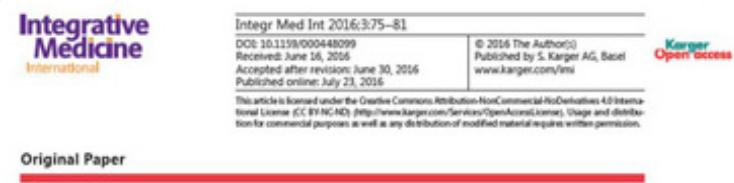

\section{A Laser Watch for Simultaneous Laser Blood Irradiation and Laser Acupuncture at the Wrist}

Gerhard Litscher Daniela Litscher

Research Uni for Complementary and Integrative Laser Nediciese. Research Unin for Centre Graz. Medicaling University of Graz Graz. Austria

(c)
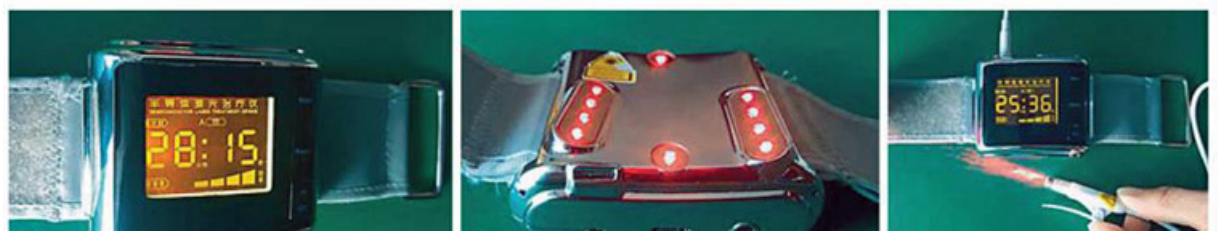

(d)

Figure 10. Laser watch $(\mathbf{a}, \mathbf{d})$ for simultaneous laser acupuncture and laser blood irradiation $(\mathbf{b}, \mathbf{c})[10]$.

17 August 2016: Hubei University of Chinese Medicine in Graz, Austria (Figure 11) [3]. 


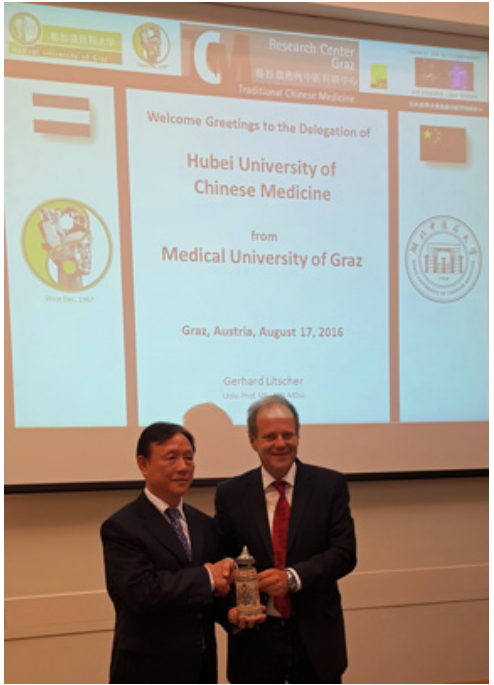

(a)

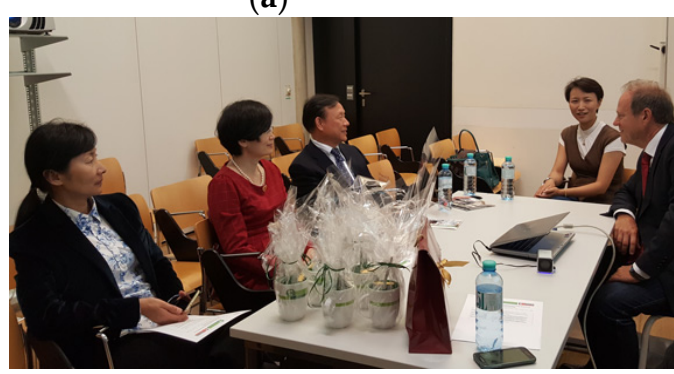

(c)

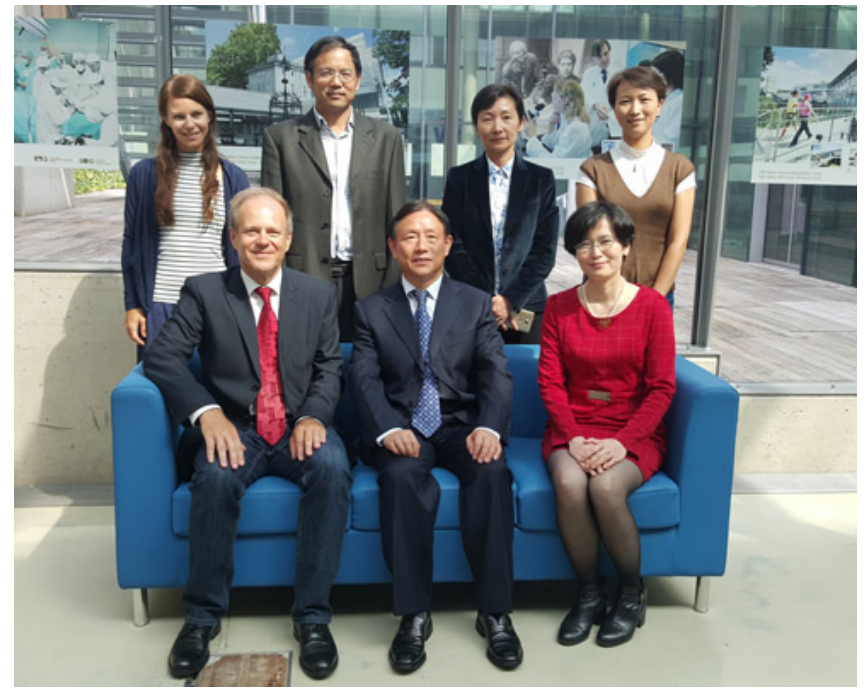

(b)

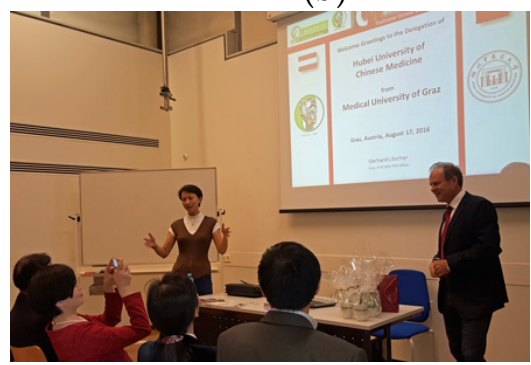

(d)

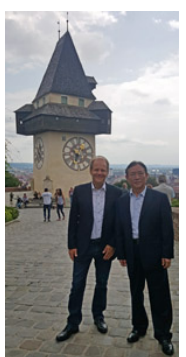

(e)

Figure 11. Guests from Hubei University of Chinese Medicine (a-e): Prof. Wang Hua, former President of Hubei University of Chinese Medicine (a left), Prof. Liang Fengxia, Deputy Director of Acupuncture and Moxibustion Institute (b middle), Prof. Qi Fengjun, Acupuncture and Moxibustion and Orthopedics College, Prof. Zhou Zhongyu, Department of Acupuncture and Moxibustion, Traditional Chinese Medicine Hospital of Hubei Province with Prof. Wang Lu, Dr. Daniela Litscher and Prof. Gerhard Litscher.

Established in 1958, the Hubei University of Chinese Medicine has three secondary schools, four affiliated hospitals, four State-Level (highest level) Medical Research Centers and 10 Research Institutions. The university occupies $0.65 \mathrm{~km}^{2}$ with a total construction of about $470,000 \mathrm{~m}^{2}$. The university has 15 departments, 17 specialties for bachelor's degree and 9 specialties for professional training, 19 specialties for master's degree and 12 specialties for doctor degree; more than 60 bases for clinical practice, including 6 affiliated hospitals, 21 State-Level, Province-Level or College-Level laboratories for teaching. At present the university has about 15,000 students.

Acupuncture is one of the key disciplines of research of this renowned university. The Medical University of Graz (Prof. Gerhard Litscher) has a close cooperation with Hubei University of Chinese Medicine (with Prof. Wang Hua and Prof. Liang Fengxia) on the topic of high-tech acupuncture research. Within the last years, joint SCI/PubMed-listed publications have been published. Prof. Litscher from the Medical University of Graz is Visiting Professor at Hubei University of Chinese Medicine and at the Hubei Provincial Collaborative Innovation Center of Preventive Treatment by Acupuncture and Moxibustion (Director: Prof. Wang Hua).

5 September 2016: Acupuncture Congress-Experts. Timmendorfer Strand, Germany (Figure 12). 


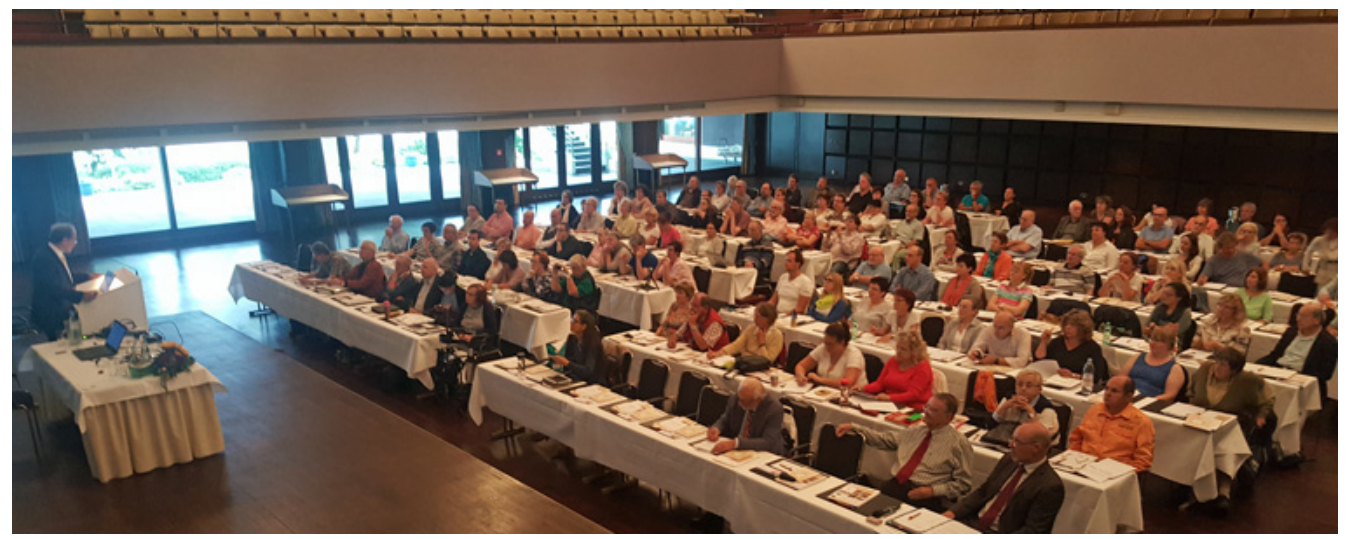

Figure 12. Opening lecture: G. Litscher, 5 September 2016, 8:30-9:30-Innovations and selective trends in the development of ear acupuncture research.

16-17 September 2016: International Laser Medical Congress, Sandvika, Norway (Figure 13).

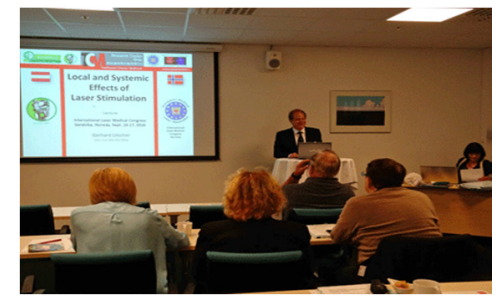

(a)

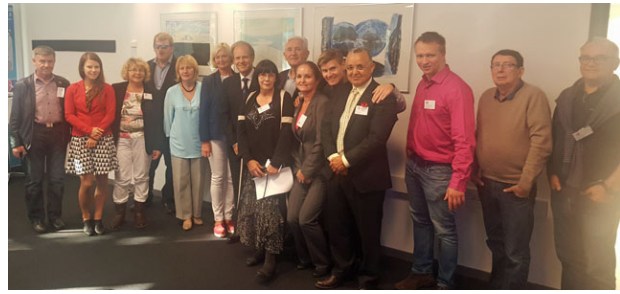

(b)

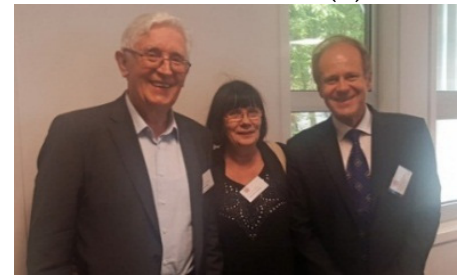

(c)

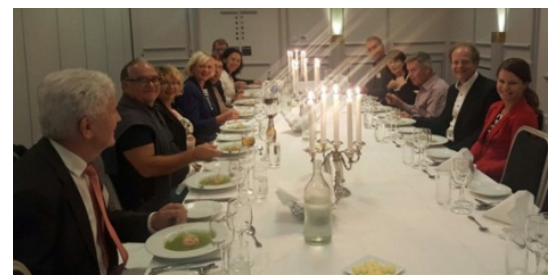

(d)

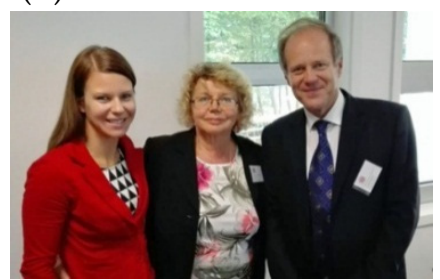

(e)

Figure 13. Sandvika Congress (a-e). Prof. Juozas V. Vaitkus, President of Lithuanian Physical Society (c left), Dr. Anne Harila, President of EMLA Scandinavia (c middle), Dr. Daniela Litscher (e left), Dr. Draga Marti, President of EMLA Switzerland (e middle) and Prof. Gerhard Litscher. Keynote Lecture: G. Litscher (a), Local and systemic effects of laser stimulation. Lecture: D. Litscher, Yellow laser: a new option for prevention and treatment of lifestyle-related diseases. Lecture: G. Litscher, Laser watch-a new option for simultaneous laser blood irradiation and laser acupuncture.

23 September 2016: Meeting of Sino-Austrian auricular acupuncture leaders, Beijing, China (Figure 14) [2]. 


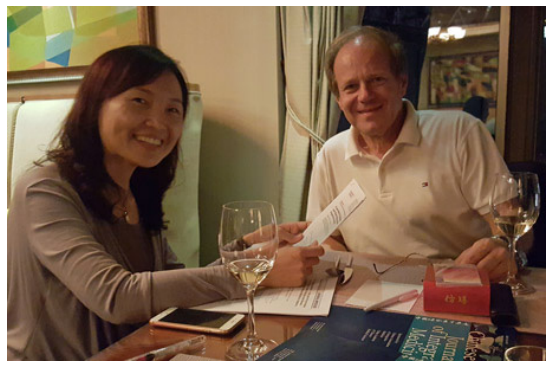

(a)

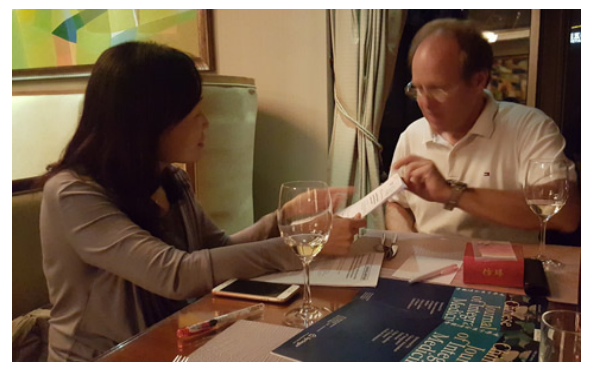

(b)

Figure 14. Editorial discussion. Prof. Rong Peijing, Vice director of Auricular Acupuncture Professional Committee, China Association of Acupuncture and Moxibustion (CAAM), Professor at Institute of Acupuncture and Moxibustion at China Academy of Chinese Medical Sciences $(\mathbf{a}, \mathbf{b}$ left) and Prof. Gerhard Litscher, Beijing, China, 23 September 2016.

23 September 2016: Meeting-Hospital of Acupuncture and Moxibustion of China Academy of Chinese Medical Sciences (CACMS), Beijing, China (Figure 15).

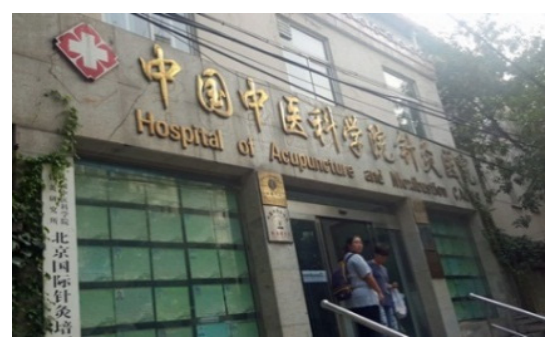

(a)

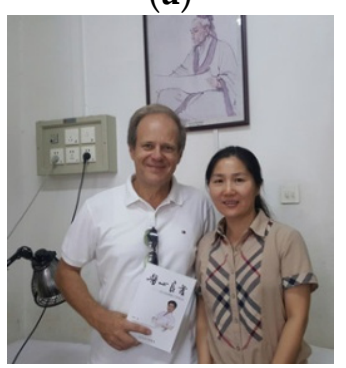

(c)

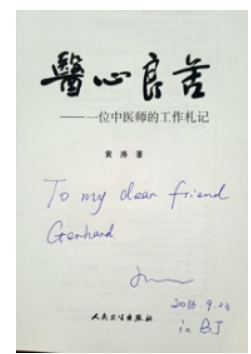

(b)

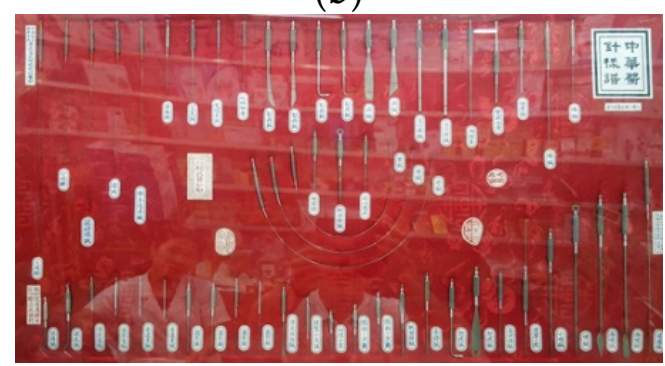

(d)

Figure 15. Hospital of Acupuncture and Moxibustion of CACMS (a). New book (b) from Assoc. Prof. Dr. Huang Tao (c right) and Prof. Gerhard Litscher, Beijing, China. Historical acupuncture needles $(\mathbf{d})$.

23 September 2016: Editor's Meet in Beijing-Medicines, Beijing, China, G. Litscher: Editor-in-chief of Medicines (Figure 16). 


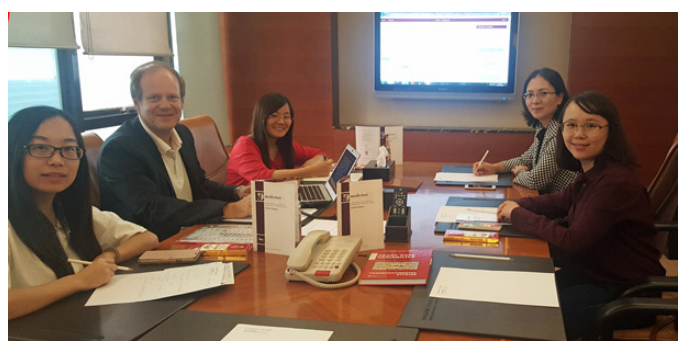

(a)

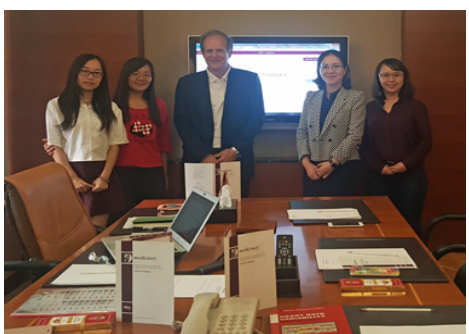

(b)

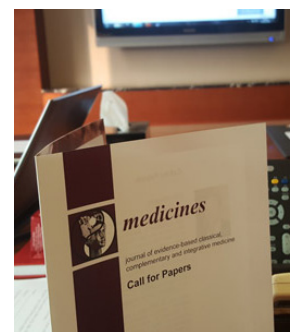

(c)

Figure 16. Editor-in-chief Prof. Gerhard Litscher with the editorial team of Medicines in Beijing, China. Managing editor Winnie Gong (a middle), former managing editor Xiaoyan Chen (a left) and assoc. editor-in-chief Prof. Gao Xinyan (a second from right).

24 September 2016: Meeting at Beijing Hospital of TCM affiliated to Capital Medical University Beijing, China (Figure 17).

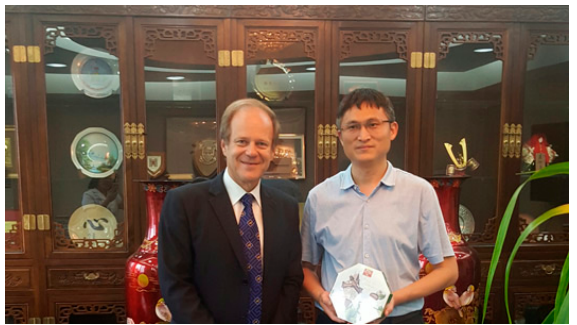

(a)

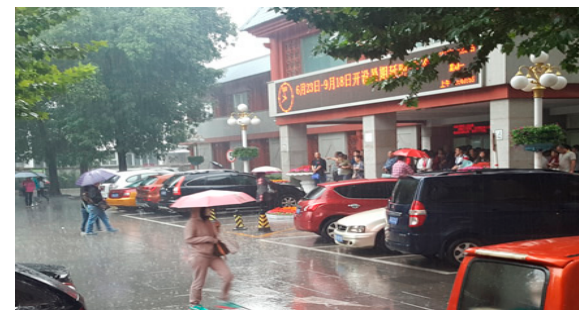

(c)

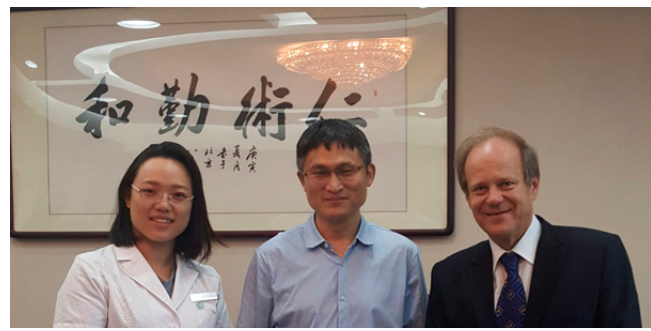

(b)

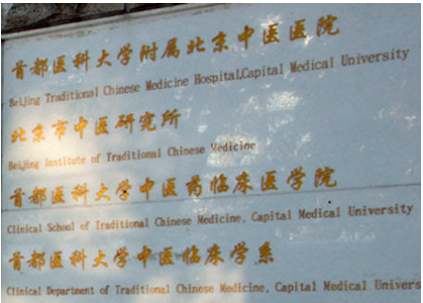

(d)

Figure 17. Prof. Liu Cun-Zhi (Vice-Director-China) of the Sino-Austrian Research Center for High-Tech Acupuncture and Clinical and Experimental Integrative Medicine (a right, $\mathbf{b}$ middle) and Prof. Gerhard Litscher (Director of the Center-Austria). Beijing Hospital of TCM (c,d).

26 September 2016: Meeting at Tong Ren Hospital affiliated to Capital Medical University Beijing, China (Figure 18).

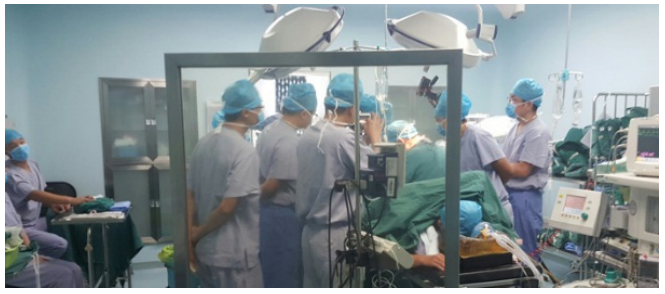

(a)

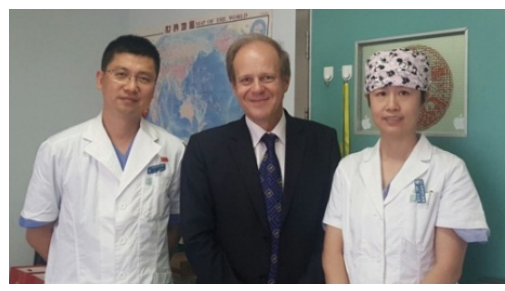

(b)

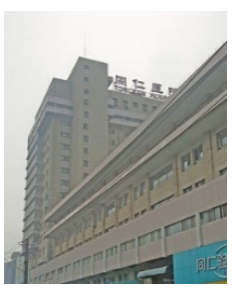

(c)

Figure 18. P Tong Ren Hospital (a,c). Prof. Pan, Head of the Department of Anesthesiology (b left), Dr. Sun Yanxia (b right) and Prof. Gerhard Litscher (b middle). 
26 September 2016: China Academy of Chinese Medical Sciences, Institute of Acupuncture and Moxibustion, Beijing, China (Figure 19).

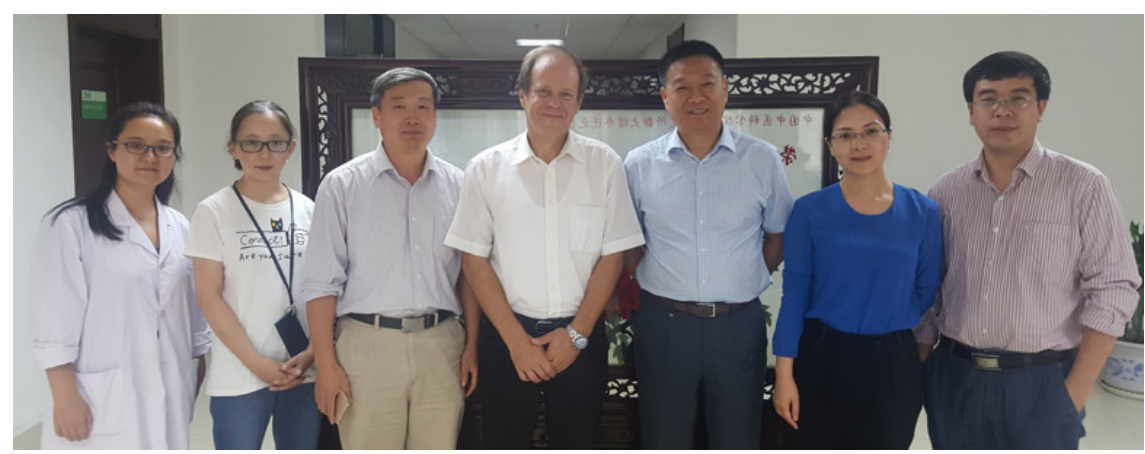

Figure 19. Joint TCM project discussion at CACMS.

27 September 2016: Annual report meeting of guest professor at Hubei University of Chinese Medicine, Wuhan, China (Figure 20).

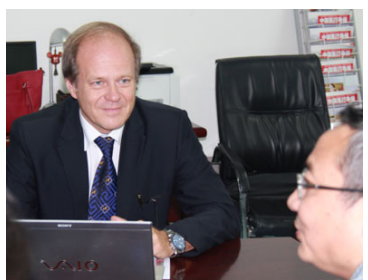

(a)

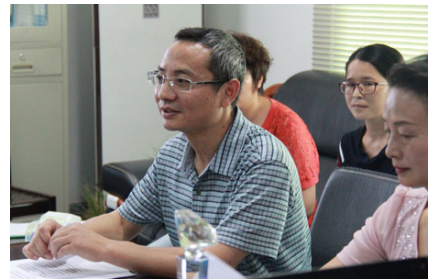

(b)

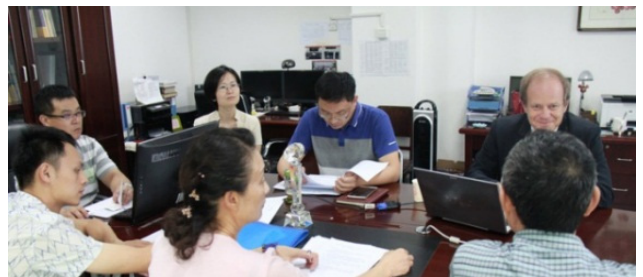

(c)

Figure 20. G. Litscher (a) Visiting Professor at Hubei University of Chinese Medicine, Wuhan, China, 27 September 2016. Academic discussion with the leaders of Hubei University of Chinese Medicine (b,c).

27 September 2016: Lecture at Hubei University of Chinese Medicine, Wuhan, China (Figure 21).

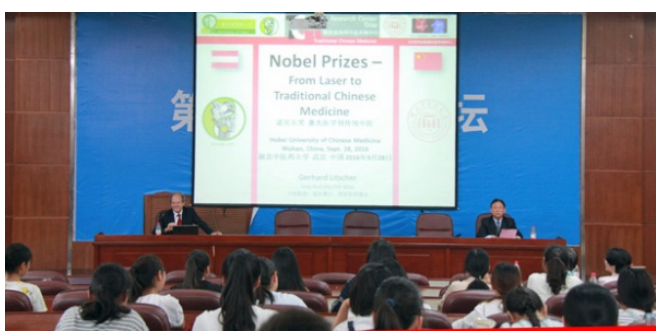

(a)

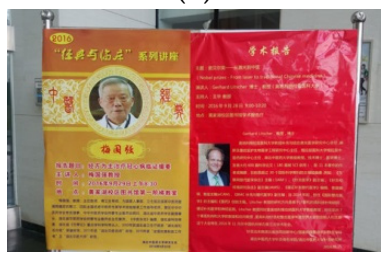

(c)

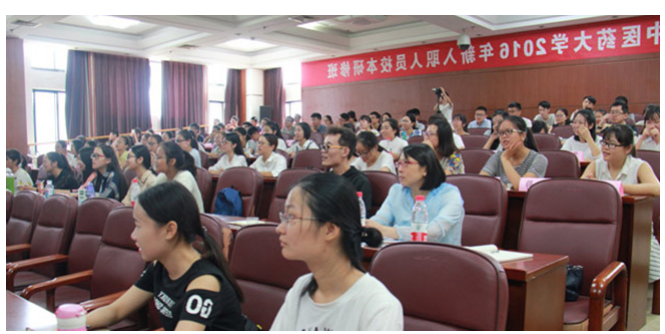

(b)

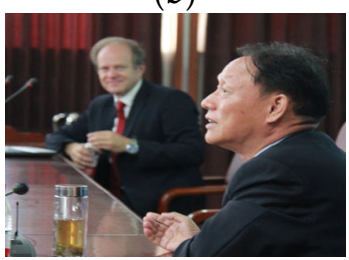

(d)

Figure 21. Lecture: G. Litscher (a), Nobel Prizes-From Laser to Traditional Chinese Medicine. Prof. Wang Hua, former President of Hubei University of Chinese Medicine (d). Lecture room (b) and announcement (c). 
28 September 2016: WFAS-Education Working Committee, Wuhan, China (Figure 22).

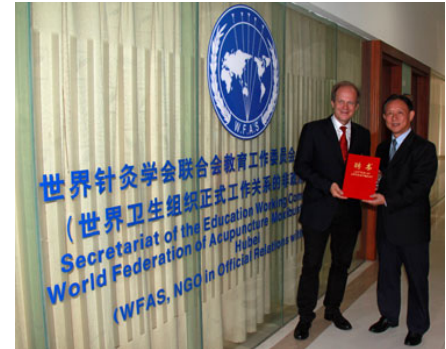

(a)

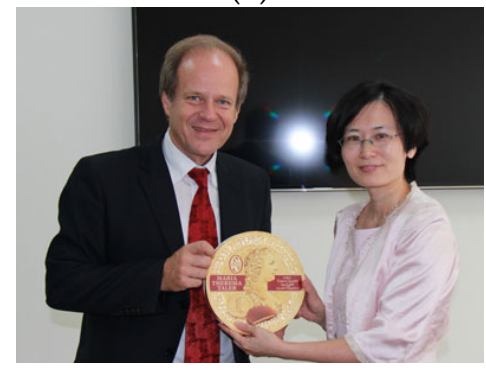

(c)

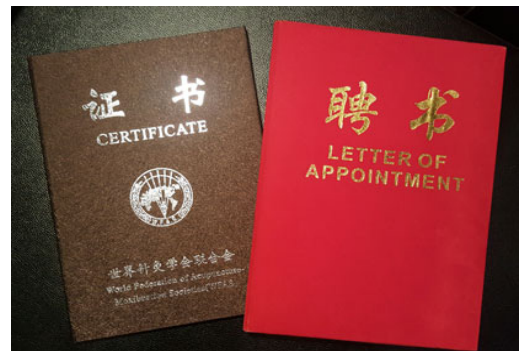

(b)

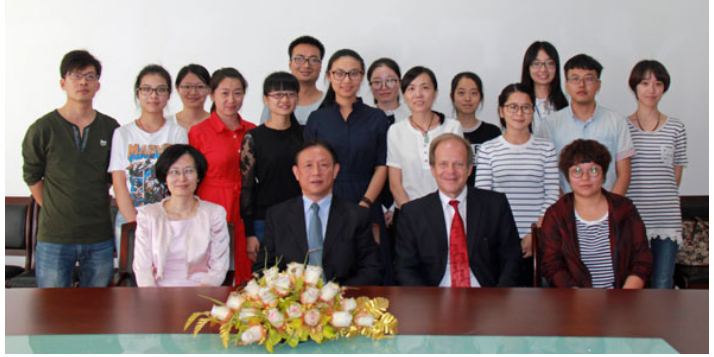

(d)

Figure 22. Prof. Gerhard Litscher was appointed as a Member of the Education Working Committee of the World Federation of Acupuncture-Moxibustion Societies in Wuhan/China for a term of 4 years $(\mathbf{a}-\mathbf{d})$.

30 September 2016: Discussion about "Phytopharm 2017" and 10th Anniversary of the TCM Research Center Graz in 2-5 July 2017, Graz, Austria (Figure 23).

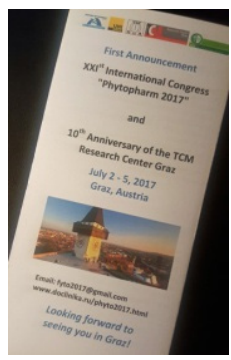

(a)

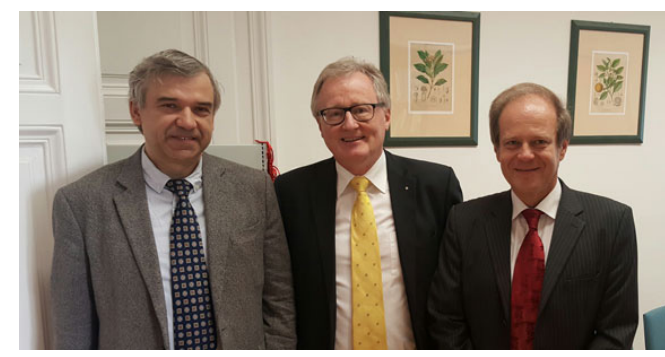

(b)

Figure 23. Phytopharm 2017 (a). Prof. Alexander Shikov, St. Petersburg, Russia (b left), Prof. Rudolf Bauer (b middle) and Prof. Gerhard Litscher (b right), Graz, Austria (Organizers) [13].

15-16 October 2016: Laser Workshop, Munich, Germany (Figure 24). 


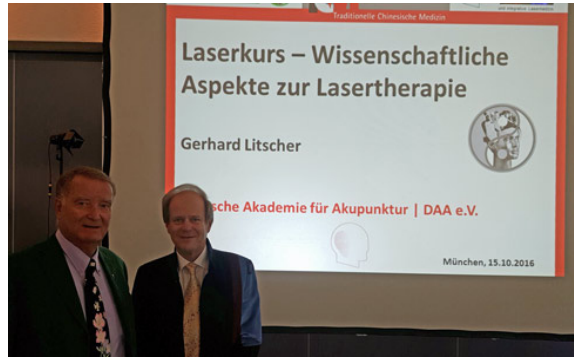

(a)

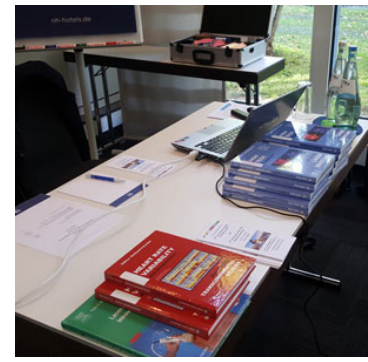

(b)

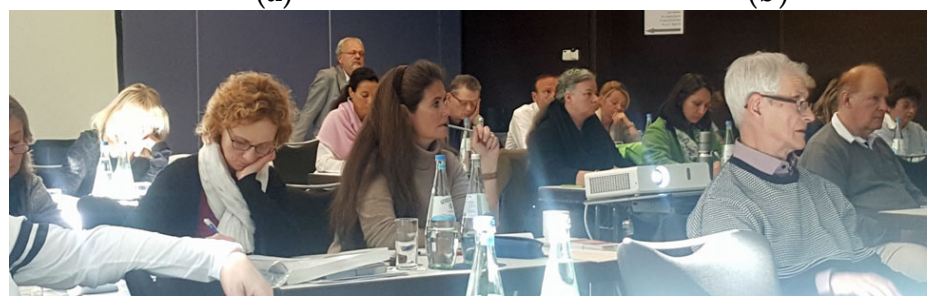

(c)

Figure 24. Prof. Frank Bahr, Munich, Germany (a left) and Prof. Gerhard Litscher (a right), Graz, Austria were the oganizers of the workshop in Munich $(\mathbf{b}, \mathbf{c})$.

21-22 October: TCM Symposium, Krems, Austria (Figure 25).

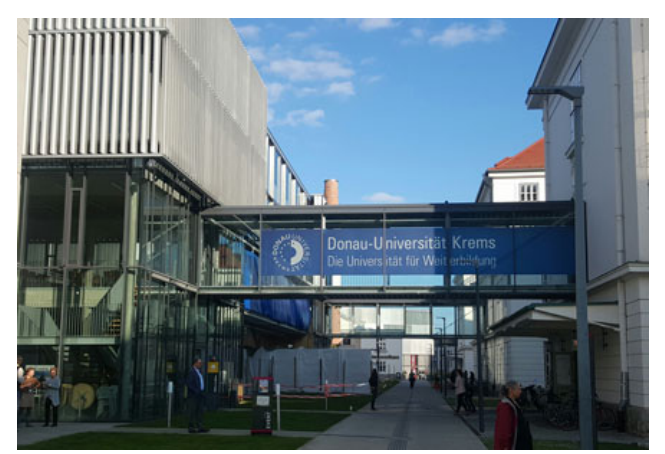

(a)

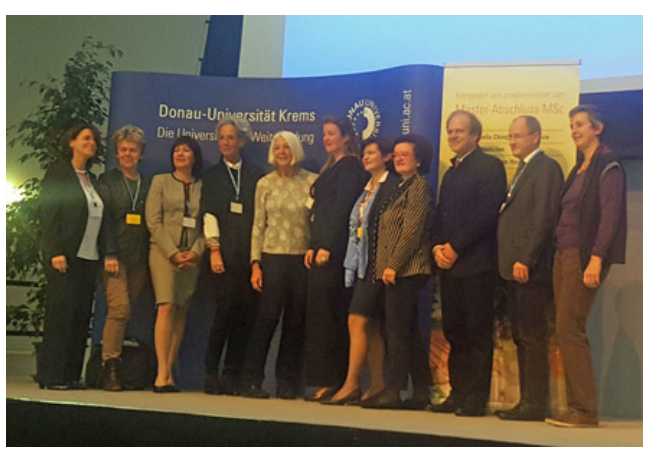

(b)

Figure 25. Danube University Krems (a) and participants (b). Prof. Gerhard Litscher, Lecture + Workshop (Laser Acupuncture and Innovative Laser Medicine).

9 November 2016: Peking University-Health Science Center. Eurasia Pacific Uninet (EPU) (Figure 26).

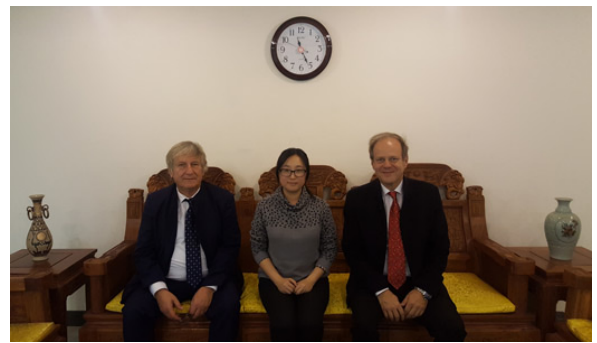

(a)

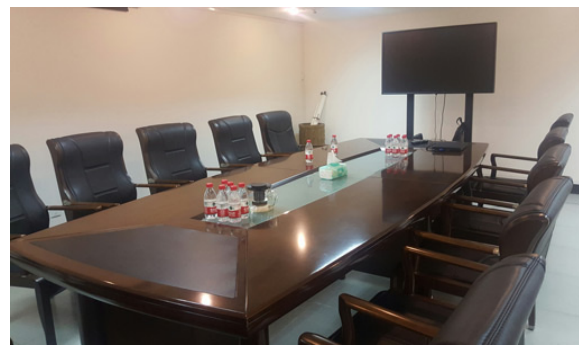

(b)

Figure 26. EPU PhD-interviews. Profs. D. Rausch (a left) and G. Litscher (a right) at Peking University (b), Beijing, China. 
9-20 November: USTB-University of Science and Technology Beijing, China (Figure 27).

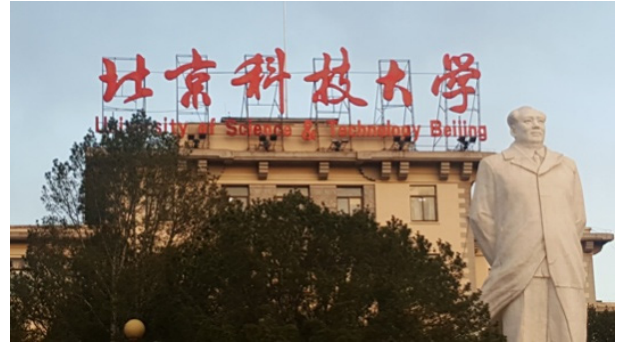

(a)

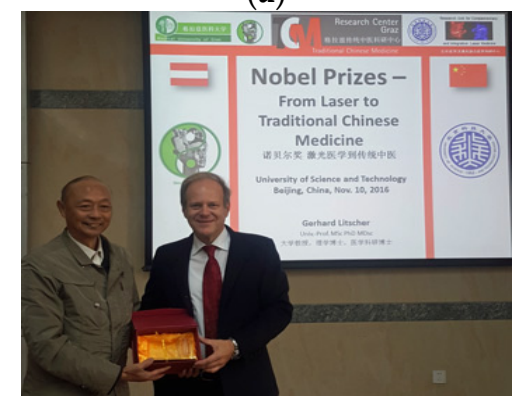

(c)

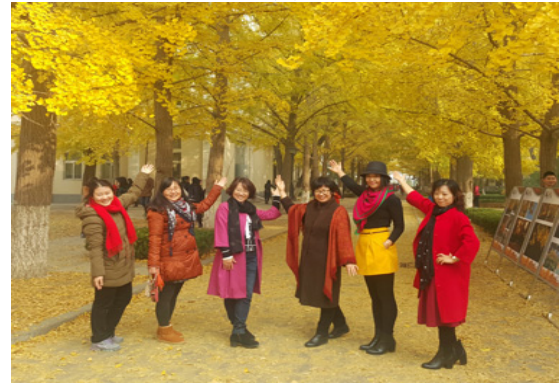

(e)

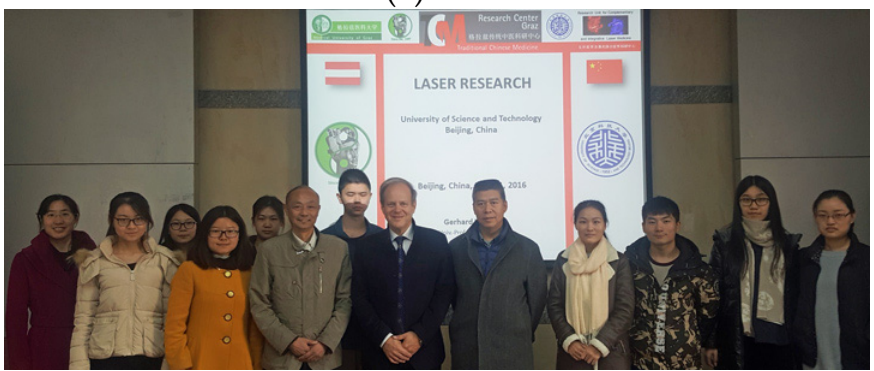

(g)

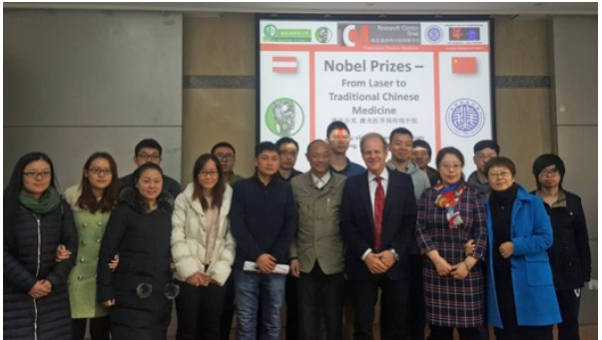

(b)

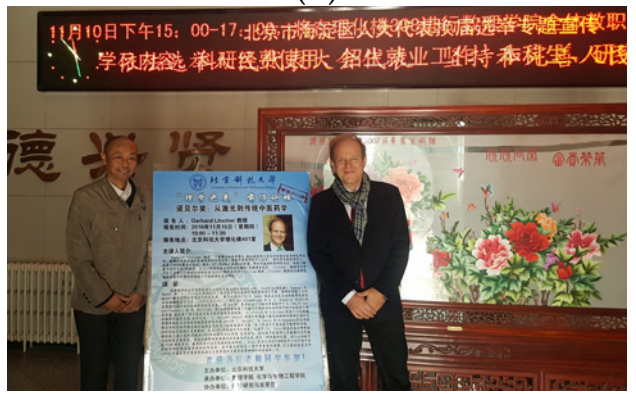

(d)

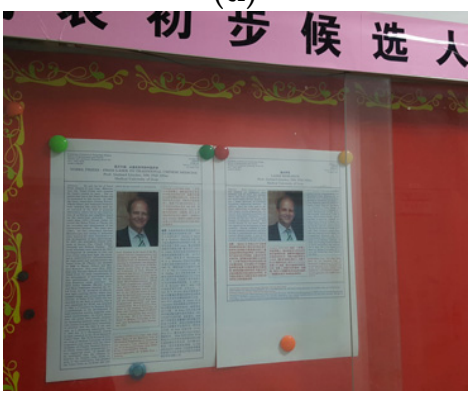

(f)

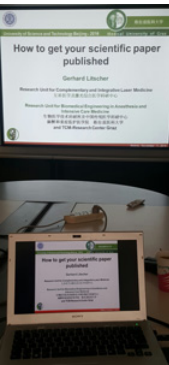

(h)

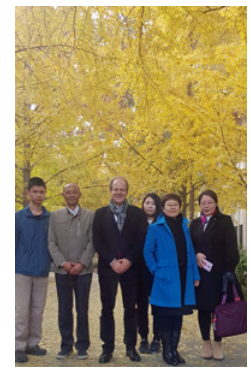

(i)

Figure 27. G University of Science and Technology Beijing (a-i). G. Litscher: lectures as guest professor at USTB (b-d,f-i), Prof. Min Lequan (c,d left). Lectures and project discussions.

12 November 2016: People's Liberation Army General Hospital Beijing, China (Figure 28). 


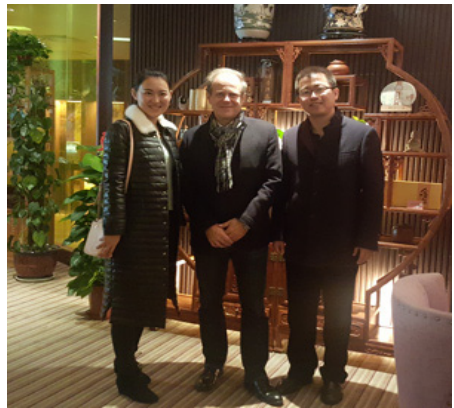

(a)

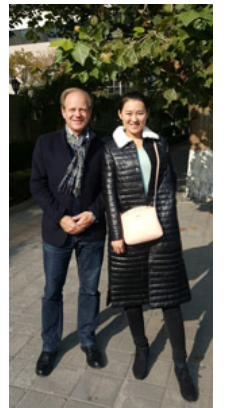

(b)

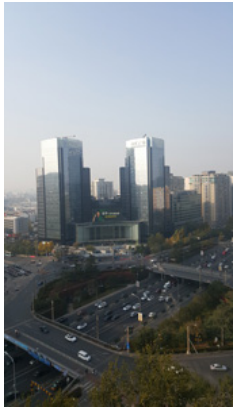

(c)

Figure 28. Discussion-clinical study: acupotomy. Prof. Ding Yu (a right), Dr. Wang Huan (a left, b right) and Prof. Gerhard Litscher (a middle, b left), Beijing (c), China.

14 November 2016: Lecture at Tong Ren Hospital affiliated to Capital Medical University, Department of Anesthesiology, Beijing, China (Figure 29).

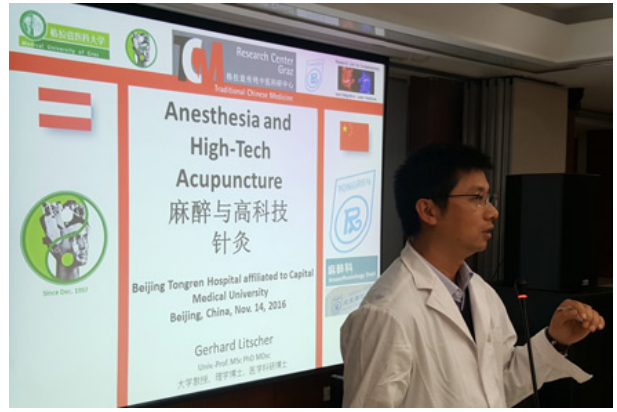

(a)

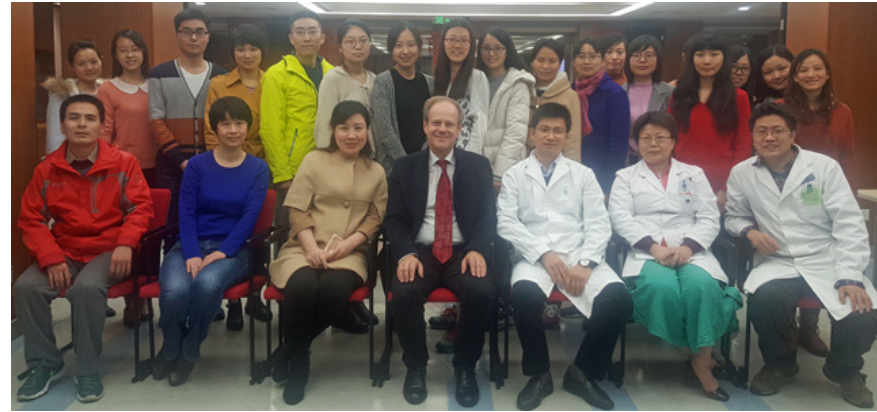

(b)

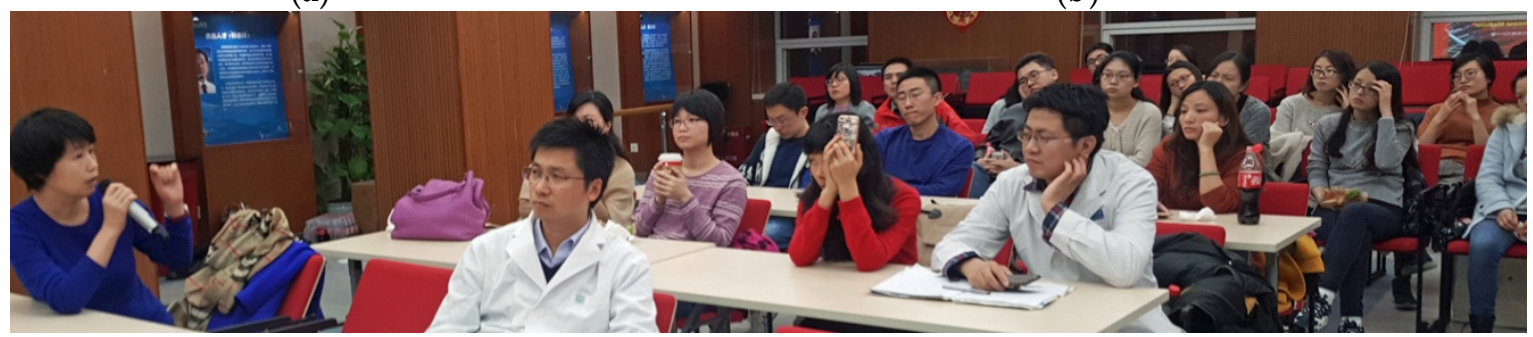

(c)

Figure 29. G. Litscher: Lecture-Anesthesia and High-Tech Acupuncture. Prof. Pan, Head of the Department of Anesthesiology (a), Dr. Sun Yanxia (c left) and Prof. Gerhard Litscher (b middle).

16-19 November 2016: 3rd Annual World Congress High-Tech Acupuncture and Integrative Medicine and 1st Annual World Congress Modern Chinese Medicine, Nanjing, China.

Venue: Nanjing International Youth Convention Center, China.

Congress Chair of both Congresses: Gerhard Litscher, Medical University of Graz, Austria, Europe. Congress Co-chair: Lu Wang, Medical University of Graz, Austria, Europe. Executive Chair: Xiaodan Mei, BIT, Dalian, China.

Experts from many different countries and regions from all over the world have presented their research results. Altogether, 70 speakers have presented their lectures and workshops during the three days.

Opening Ceremony: Three Nobel Prize winners (Figure 30) at the World Congress (Figure 31). 


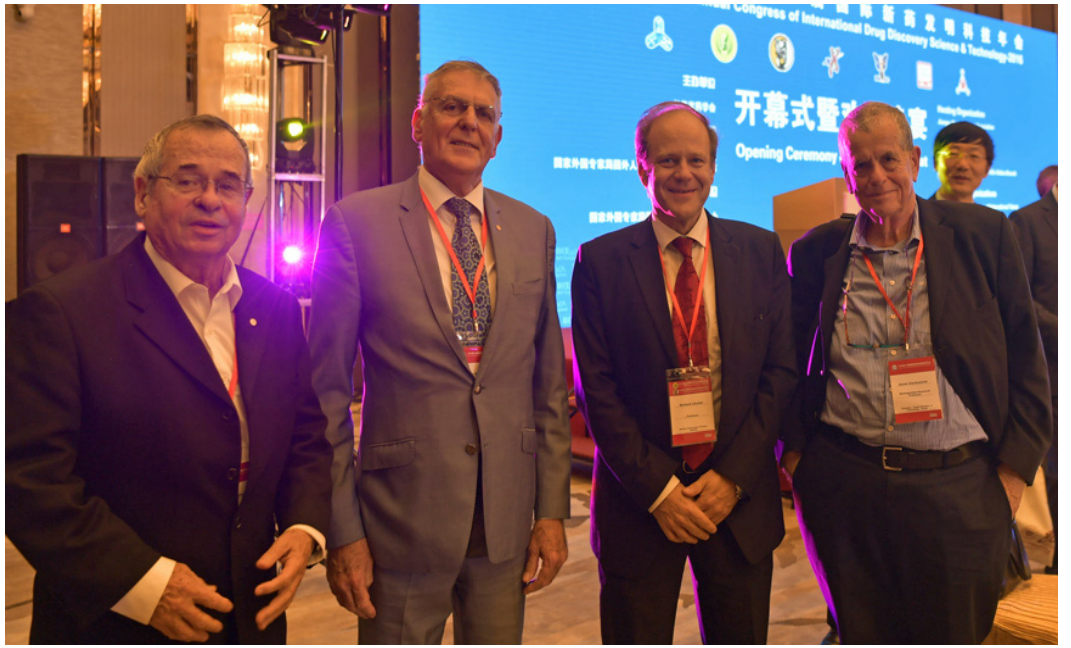

Figure 30. Congress Chair Gerhard Litscher together with three Nobel Prize Winners: Ariel Warshel (left) 2013, Dan Shechtman (middle) 2011 and Aaron Ciechanover (right) 2004.

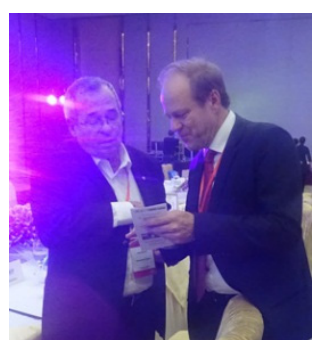

(a)

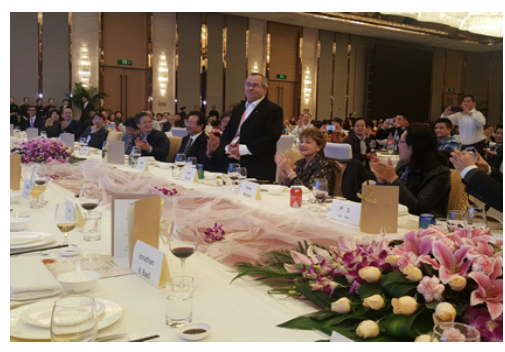

(b)

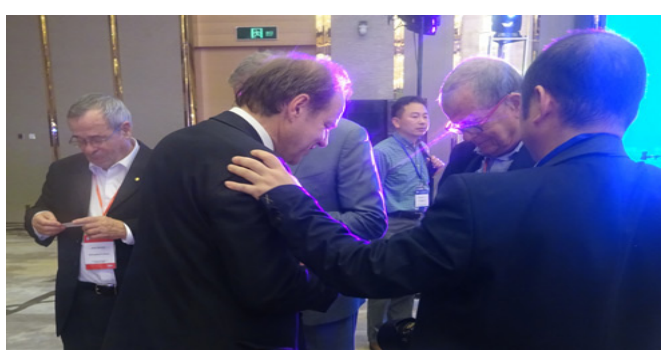

(c)

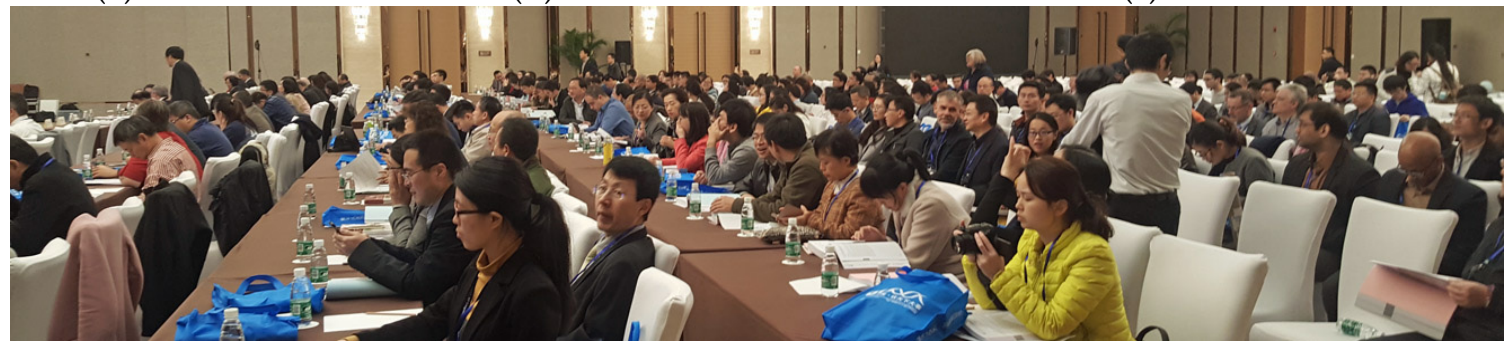

(d)

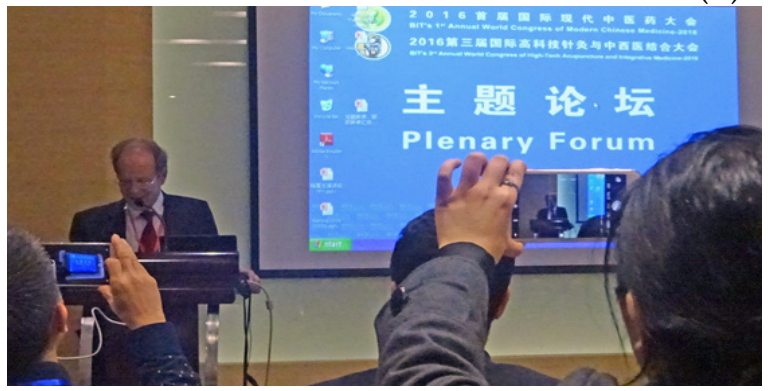

(e)

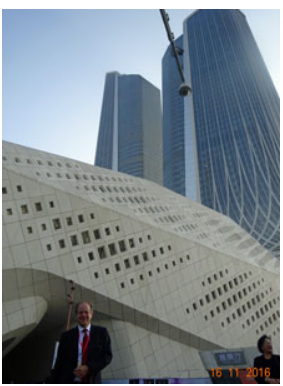

(f)

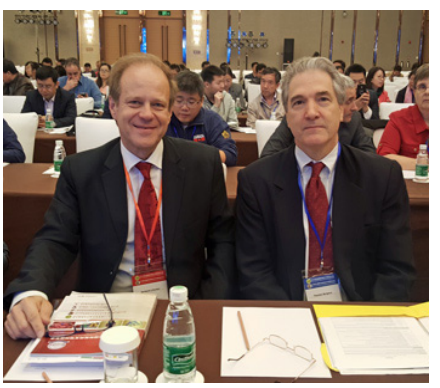

$(\mathrm{g})$

Figure 31. Cont. 


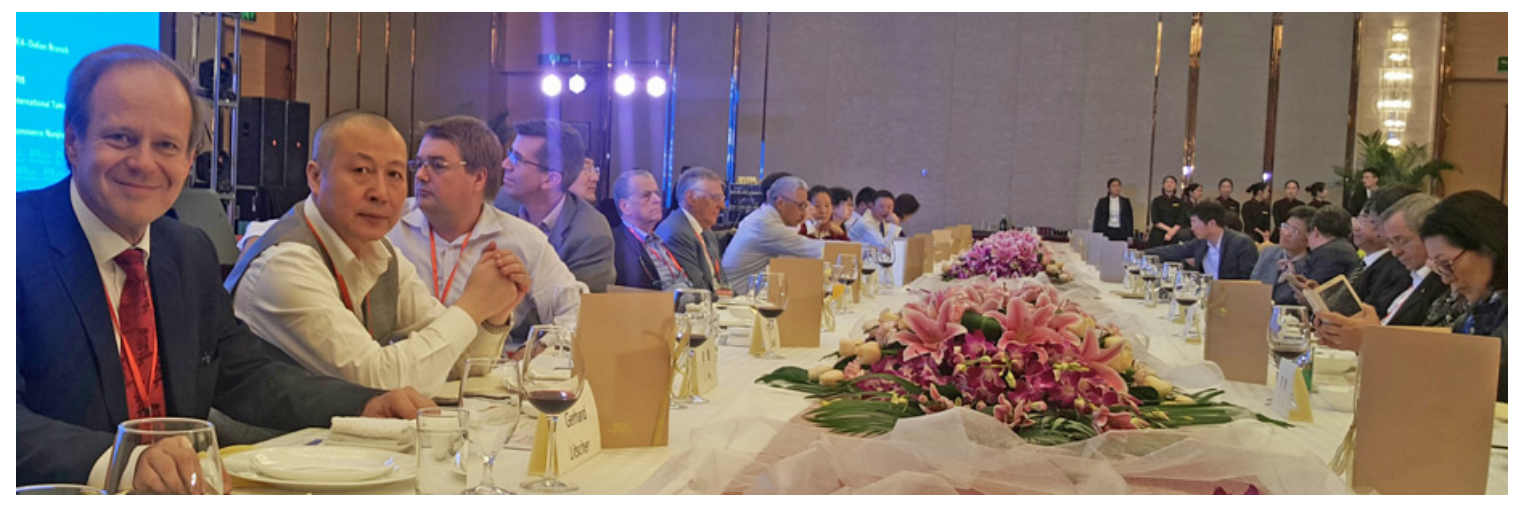

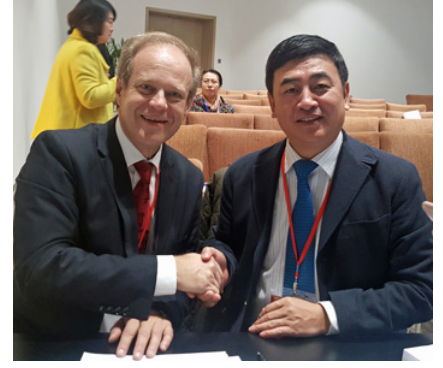

(i)

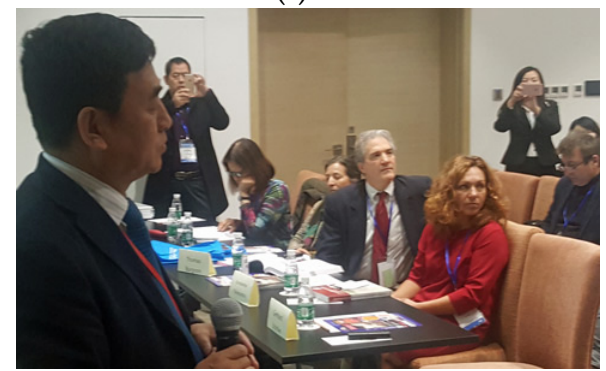

(k)

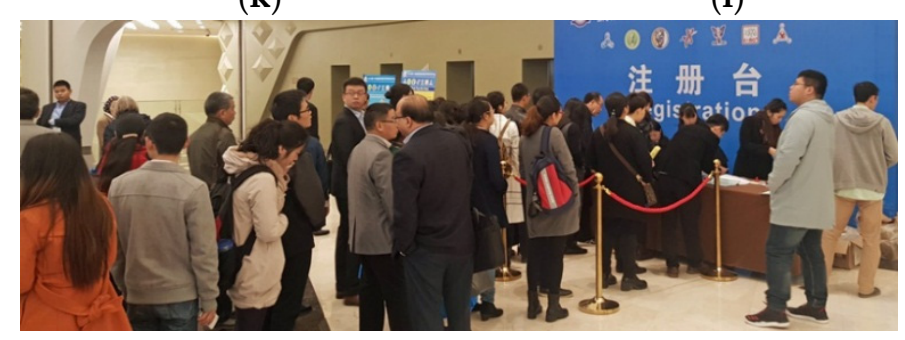

(n)

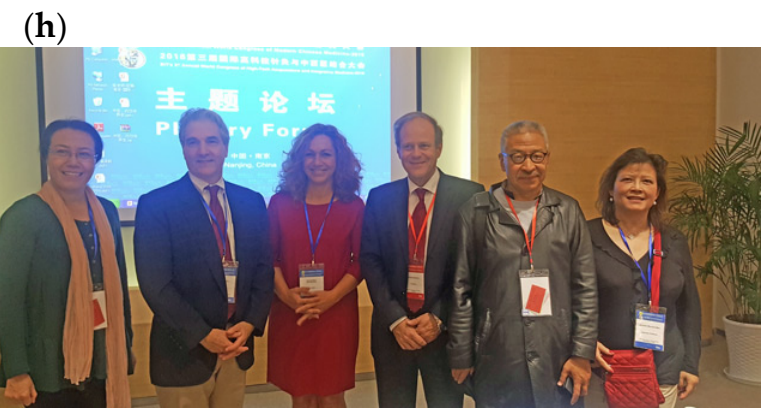

(j)

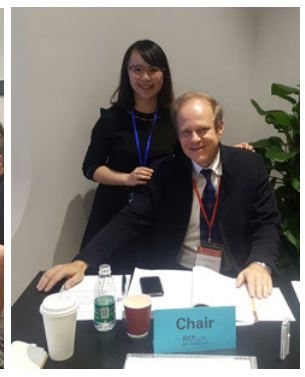

(1)

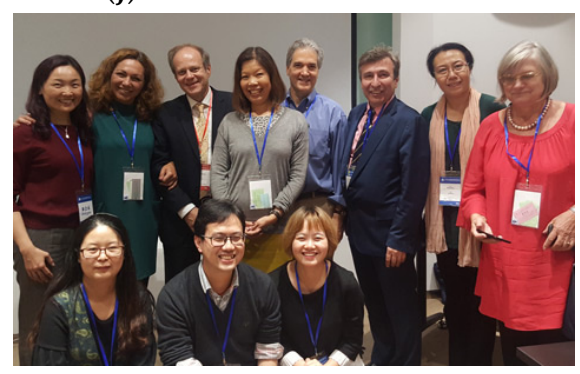

(m)

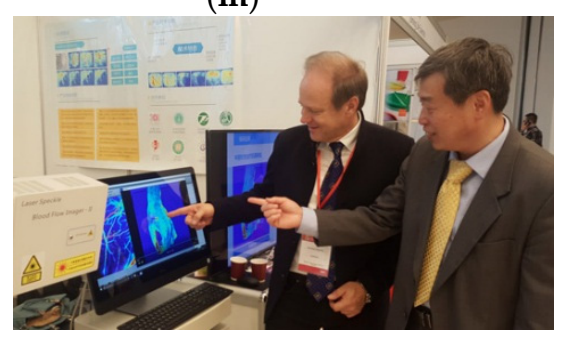

(o)

Figure 31. Impressions from the 3rd Annual World Congress High-Tech Acupuncture and Integrative Medicine and the 1st Annual World Congress Modern Chinese Medicine, Nanjing, China (a-o).

18 November 2016: Discussion about tradition and innovation of auricular acupuncture for the Singapore conference in August 2017, Nanjing, China (Figure 32). 


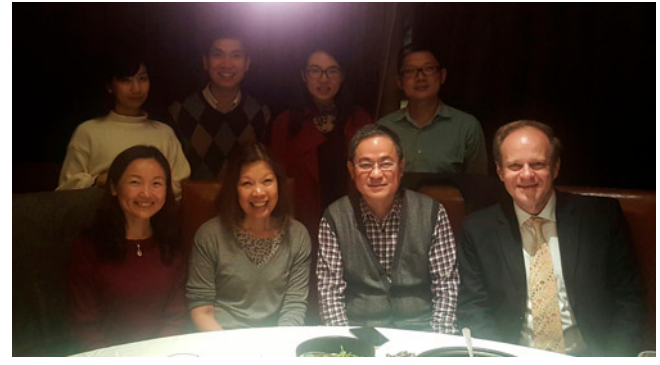

(a)

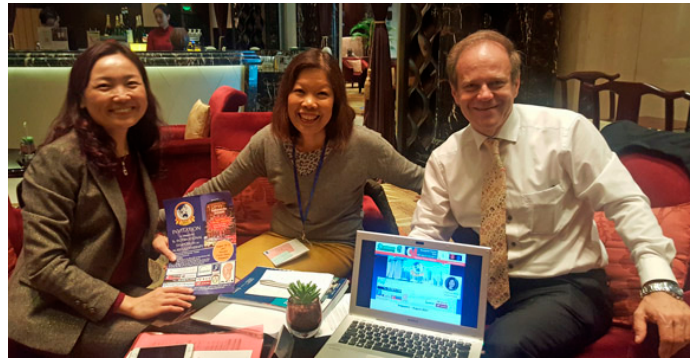

(b)

Figure 32. Discussion at Nanjing Medical University. Prof. Rong Peijing, Vice Director of Auricular Acupuncture Professional Committee, China Association of Acupuncture and Moxibustion (CAAM) (a,b left), Dr. Im Quah Smith, Roseville, Australia, Chair of the Singapore Congress (2017) (a,b middle) and Prof. Gerhard Litscher (a,b right). Nanjing, China.

3 December 2016: Traditional Chinese Medicine-Master of Science Medical University of Vienna, Austria (Figure 33).

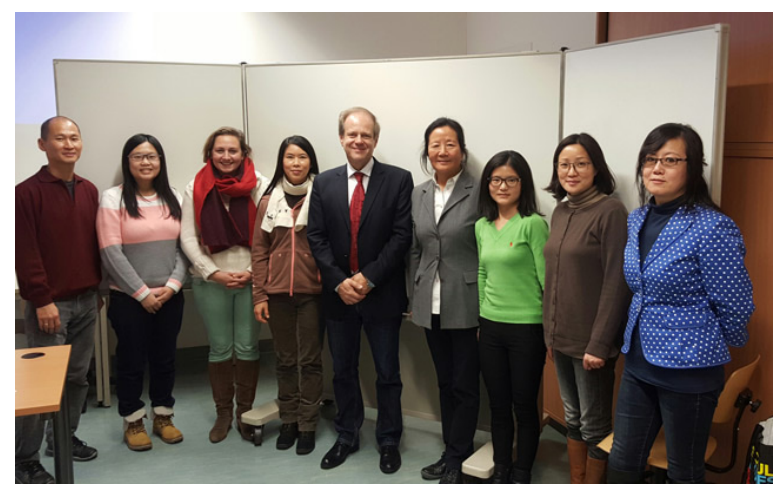

(a)

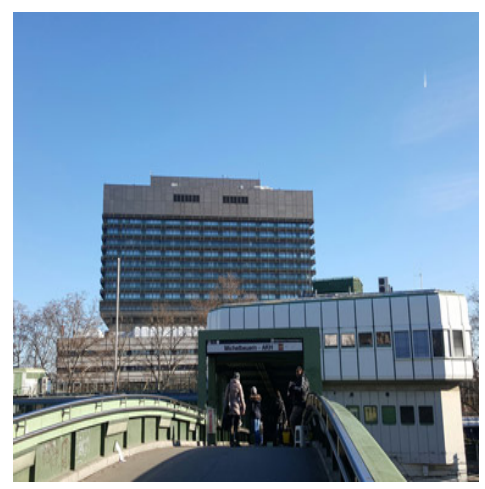

(b)

Figure 33. Medical University of Vienna (b). Lecture on the topic 'Experimental Acupuncture'-G. Litscher, Austria. Assoc. Prof. PD Dr. Ma Yan (a forth from left), Prof. Gerhard Litscher (a middle), and MSc candidates.

15 December 2016: Meeting of Eurasia Pacific Uninet (EPU) Scholars. University of Veterinary Medicine, Vienna, Austria (Figure 34).

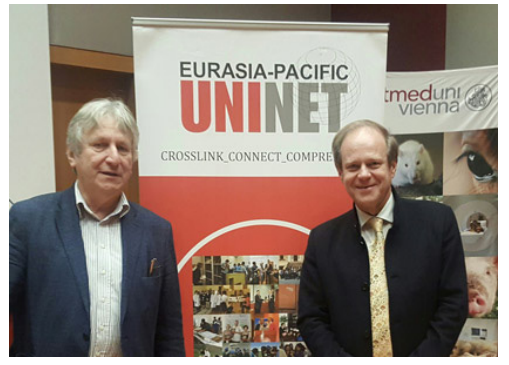

(a)

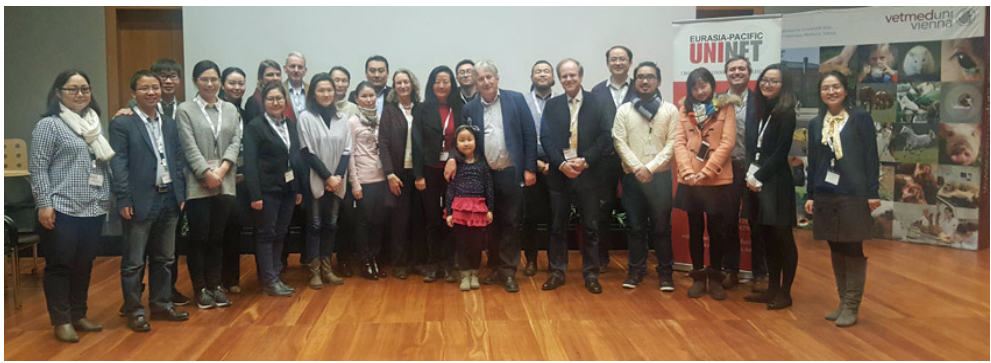

(b)

Figure 34. Keynote lecture G. Litscher (a right): 'Exploring Acupuncture within an International High-Tech Network'. EPU network president Prof. W.D. Rausch (a left) and EPU scholars (b). 
Acknowledgments: The scientific work within the cooperation with China was supported by the Austrian Federal Ministry of Science, Research and Economy and by Eurasia Pacific Uninet (EPU). The contribution will also be published in the annual EPU report.

Conflicts of Interest: The author declares no conflict of interest.

\section{References}

1. Litscher, D.; Litscher, G. The history of liquid ear acupuncture and the current cientific state of the art. J. Pharmacopunct. 2016, 19, 109-113. [CrossRef] [PubMed]

2. Litscher, G.; Rong, P.J. Auricular acupuncture. Evid. Based Complement. Alternat. Med. 2016, 2016, 4231260. [CrossRef] [PubMed]

3. Shu, Q.; Wang, H.; Litscher, D.; Wu, S.; Chen, L.; Gaischek, I.; Wang, L.; He, W.; Zhou, H.; Litscher, G.; et al. Acupuncture and moxibustion have different effects on fatigue by regulating the autonomic nervous system: A pilot controlled clinical trial. Sci. Rep. 2016, 6, 37846. [CrossRef] [PubMed]

4. Wang, J.; Gao, Y.; Chen, S.; Duanmu, C.; Zhang, J.; Feng, X.; Yan, Y.; Liu, J.; Litscher, G. The effect of repeated electroacupuncture analgesia on neurotrophic and cytokine factors in neuropathic pain rats. Evid. Based Complement. Alternat. Med. 2016, 2016, 8403064. [CrossRef] [PubMed]

5. Wang, J.Y.; Chen, R.B.; Chen, S.P.; Gao, Y.H.; Zhang, J.L.; Feng, X.M.; Yan, Y.X.; Liu, J.L.; Gaischek, I.; Litscher, D.; et al. Electroacupuncture reduces the effects of acute noxious stimulation on the electrical activity of pain-related neurons in the hippocampus of control and neuropathic pain rats. Neural Plast. 2016, 6521026. [CrossRef] [PubMed]

6. Litscher, D.; Litscher, G. Modernization of acupuncture education in Europe and China: A report from Austria. OBM Integrat. Complement. Med. 2016, 1. [CrossRef]

7. Litscher, D.; Litscher, G. China's Tu Youyou, Nobel Laureate in medicine 2015, and relationships with the TCM Research Center Graz at the Medical University. Integrat. Med. International. 2016, 3, 1-9. [CrossRef]

8. Litscher, D.; Litscher, G. Aktuelle Aspekte zur TCM-Ausbildung und -praxis in China. Akupunkt. Aurikulomedizin 2016, 42, 32-35. [CrossRef]

9. Litscher, G. ICM-OBM-There's no better way to publish your complementary medical, basic and clinical research results. OBM Integrat. Complement. Med. 2016, 1. [CrossRef]

10. Litscher, G.; Litscher, D. A laser watch for simultaneous laser blood irradiation and laser acupuncture at the wrist. Integr. Med. Internat. 2016, 3, 75-81. [CrossRef]

11. Pang, B.; Zhang, Q.; Cheng, G.Y.; Cheng, W.P.; Litscher, D.; Wang, L.; Sheng, Z.M.; Gaischek, I.; Sun, Z.R.; Litscher, G. Effects of acupuncture at the left Weizhong acupoint on heart rate variability in thirty post-stroke patients-Results from a transcontinental teleacupuncture study. OBM Integrat. Complement. Med. 2016, 1. [CrossRef]

12. Weber, M.; Litscher, G. ISLA weiterhin auf Erfolgswelle. Akupunkt. Aurikulomedizin 2016, 42, 9. [CrossRef]

13. Phytopharm 2017. Available online: www.doclinika.ru/phyto2017.html (accessed on 17 February 2017).

(C) 2017 by the author. Licensee MDPI, Basel, Switzerland. This article is an open access article distributed under the terms and conditions of the Creative Commons Attribution (CC BY) license (http:/ / creativecommons.org/licenses/by/4.0/). 